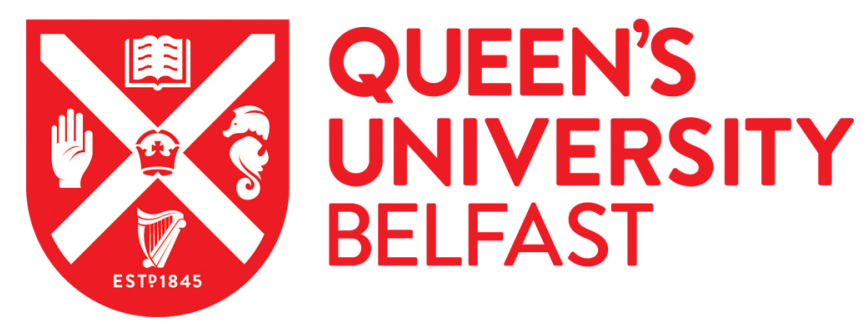

\title{
Flow patterns and pressure drop of ionic liquid-water two-phase flows in microchannels
}

Tsaoulidis, D., Dore, V., Angeli, P., Plechkova, N. V., \& Seddon, K. R. (2013). Flow patterns and pressure drop of ionic liquid-water two-phase flows in microchannels. International Journal of Multiphase Flow, 54, 1-10. https://doi.org/10.1016/j.ijmultiphaseflow.2013.02.002

Published in:

International Journal of Multiphase Flow

Document Version:

Peer reviewed version

Queen's University Belfast - Research Portal:

Link to publication record in Queen's University Belfast Research Portal

\section{Publisher rights}

This is the author's version of a work that was accepted for publication in International Journal of Multiphase Flow. Changes resulting from the publishing process, such as peer review, editing, corrections, structural formatting, and other quality control mechanisms may not be reflected in this document. Changes may have been made to this work since it was submitted for publication. A definitive version was subsequently published in International Journal of Multiphase Flow, [VOL 54, (2013)]

\section{General rights}

Copyright for the publications made accessible via the Queen's University Belfast Research Portal is retained by the author(s) and / or other copyright owners and it is a condition of accessing these publications that users recognise and abide by the legal requirements associated with these rights.

Take down policy

The Research Portal is Queen's institutional repository that provides access to Queen's research output. Every effort has been made to ensure that content in the Research Portal does not infringe any person's rights, or applicable UK laws. If you discover content in the Research Portal that you believe breaches copyright or violates any law, please contact openaccess@qub.ac.uk. 


\section{Accepted Manuscript}

Flow patterns and pressure drop of ionic liquid-water two-phase flows in microchannels

Dimitrios Tsaoulidis, Valentina Dore, Panagiota Angeli, Natalia V. Plechkova, Kenneth R. Seddon

PII: S0301-9322(13)00032-3

DOI: http://dx.doi.org/10.1016/j.ijmultiphaseflow.2013.02.002

Reference: IJMF 1879

To appear in:

International Journal of Multiphase Flow

Please cite this article as: Tsaoulidis, D., Dore, V., Angeli, P., Plechkova, N.V., Seddon, K.R., Flow patterns and pressure drop of ionic liquid-water two-phase flows in microchannels, International Journal of Multiphase Flow (2013), doi: http://dx.doi.org/10.1016/j.ijmultiphaseflow.2013.02.002

This is a PDF file of an unedited manuscript that has been accepted for publication. As a service to our customers we are providing this early version of the manuscript. The manuscript will undergo copyediting, typesetting, and review of the resulting proof before it is published in its final form. Please note that during the production process errors may be discovered which could affect the content, and all legal disclaimers that apply to the journal pertain. 


\title{
Flow patterns and pressure drop of ionic liquid-water two-phase flows in microchannels
}

\author{
Dimitrios Tsaoulidis, Valentina Dore, Panagiota Angeli* \\ Department of Chemical Engineering, University College London, Torrington Place, WC1E 7JE, UK \\ Natalia V. Plechkova, Kenneth R. Seddon \\ QUILL Research centre, School of Chemistry and Chemical Engineering, The Queen's University of Belfast, Belfast BT9 5AG, UK \\ * Corresponding author: Tel.: ++44 207679 3832; Fax: ++44 207383 2348; Email: p.angeli@ucl.ac.uk
}

\section{Abstract}

The two-phase flow of a hydrophobic ionic liquid and water was studied in capillaries made of three different materials (two types of Teflon, FEP and Tefzel, and glass) with sizes between $200 \mu \mathrm{m}$ and $270 \mu \mathrm{m}$. The ionic liquid was 1-butyl-3-methylimidazolium bis $\{$ (trifluoromethyl)sulfonyl $\}$ amide, with density and viscosity of $1420 \mathrm{~kg} \mathrm{~m}^{-3}$ and $0.041 \mathrm{~kg} \mathrm{~m}^{-1} \mathrm{~s}^{-1}$, respectively. Flow patterns and pressure drop were measured for two inlet configurations ( $\mathrm{T}$ - and Y-junction), for total flow rates of $0.065-214.9 \mathrm{~cm}^{3} \mathrm{~h}^{-1}$ and ionic liquid volume fractions from 0.05 to 0.8 . The continuous phase in the glass capillary depended on the fluid that initially filled the channel. When water was introduced first, it became the continuous phase with the ionic liquid forming plugs or a mixture of plugs and drops within it. In the Teflon microchannels, the order that fluids were introduced did not affect the results and the ionic liquid was always the continuous phase. The main patterns observed were annular, plug, and drop flow. Pressure drop in the Teflon microchannels at a constant ionic liquid flow rate, was found to increase as the ionic liquid volume fraction decreased, and was always higher than the single phase ionic liquid value at the same flow rate as in the two-phase mixture. However, in the glass microchannel during plug flow, pressure drop for a constant ionic liquid flow rate was always lower than the single phase ionic liquid value. A modified plug flow pressure drop model using a correlation for film thickness derived for the current fluids pair showed very good agreement with the experimental data. 
1 Keywords: Micro-fluidics, Liquid-liquid, Pressure drop, Flow patterns, Ionic liquids

3

\section{Introduction}

Operations in microchannels have emerged as an important area of research and have found numerous applications in (bio)chemical analysis and synthesis, intensified reactors, micropower generation, fuel cells and thermal management systems (Angeli and Gavriilidis, 2008). Many of these systems involve two phases, gas-liquid or liquid-liquid. Understanding of the flow characteristics and flow patterns, pressure drop and mass/heat transfer is essential for the design and the precise control of multiphase micro-devices. Although there are many studies concerning gas-liquid flows, only limited ones have reported on the flow behaviour of two immiscible liquids in small channels.

In liquid-liquid systems, depending on the fluid properties and the channel material, either phase can wet the channel wall, and for phases with similar wettabilities both phases can intermittently adhere to the wall, rendering ordered, stable and well-defined patterns more difficult to form than in gas-liquid flows (Wegmann et al., 2006). Controlling the hydrodynamics could decrease pressure drop, improve mass transfer, and facilitate product separation from the reaction mixture (Dessimoz et al., 2008). Two-phase liquid flows in large channels are mainly dominated by inertia forces and have been investigated using experimentation together with numerical and theoretical modelling (Angeli and Hewitt, 2000 Brauner and Maron, 1992). In the case of two-phase flow in microchannels, the interfacial tension and viscous forces are significant because of the small characteristic distances and the low Re numbers $(\operatorname{Re}<2000)$, while gravity and inertia effects become negligible (Kreutzer et al., 2005; Foroughi and Kawaji, 2011).

Different patterns can be obtained in microchannels depending not only on operational conditions, such as flow rates, phase ratio and properties of the fluids (Lin and Tavlarides, 2009), but also on the geometry of the mixing zone and the channel, and the channel wall roughness and wettability (Jovanovic et al., 2011). A highly viscous oil-water system has been investigated by Salim et al. (2008) in microchannels made of quartz and glass and different flow configurations were observed depending on the fluid that was first injected into the test channel. The main flow patterns which have been observed are plug (or segmented), drop, annular and parallel flow. The formation of plug and parallel flow is controlled by the competition between viscous and surface tension forces. Plug flow in 
1 particular has been studied by many investigators (Kashid and Agar, 2007; Garstercki et al.,

2 2006; Dessimoz et al., 2008), utilising both Y- and T-junctions as mixing zones. Moreover,

3 Kashid and Agar (2007) observed that by having fluid mixing zones with different channel

4 diameters, significant changes on the plug size and thus interfacial area were obtained. They

5 found that capillary microreactors provided very large specific interfacial areas in comparison

6 to other contactors, which enhanced mass transfer rates (for water-iodine-kerosene system,

$7 \quad \mathrm{k}_{\mathrm{L}} \alpha=1311-9815 \times 10^{-4} \mathrm{~s}^{-1}$, where $\mathrm{k}_{\mathrm{L}} \alpha$ is the volumetric mass transfer coefficient). Kashid et al.

8 (2005) reported that the intensity of the internal circulations in slugs, during plug flow, and

9 therefore the overall mass transfer rate, depended on slug geometry. Plug flow has been used to enhance mass and heat transfer in a few reactions, such as nitration (Dummann et al., 2003). Annular and parallel flows were observed when the inertial forces dominated over the interfacial forces at We $>1$ (see Table 1 for a definition of dimensionless numbers) which, however, were easily destabilised by changing flow rates and volumetric flow ratios (Zhao et al. 2006; Dessimoz et al., 2008). A general criterion has been suggested by Kashid and KiwiMinsker (2011) for an a priori flow pattern identification based on the parameter $\operatorname{Re}_{\mathrm{D}} \mathrm{d}_{\mathrm{ch}} / \varepsilon_{\mathrm{D}}$. According to the authors, flow patterns were classified into three regions based on the dominant forces. Segmented (plug) flow would occur in the surface tension dominated region for $\operatorname{Re}_{\mathrm{D}} \mathrm{d}_{\mathrm{ch}} / \varepsilon_{\mathrm{D}}<0.1 \mathrm{~m}$; annular flow would occur in the inertia dominated region for $\operatorname{Re}_{\mathrm{D}} \mathrm{d}_{\mathrm{ch}} / \varepsilon_{\mathrm{D}}>0.35 \mathrm{~m}$; transitional patterns (between plug and annular flow) would appear in the transition region for $0.1 \mathrm{~m}<\operatorname{Re}_{\mathrm{D}} \mathrm{d}_{\mathrm{ch}} / \varepsilon_{\mathrm{D}}<0.35 \mathrm{~m}$. The proposed criteria were applied to different microchannel geometries i.e. rectangular, trapezoidal, and concentric, and were found to be independent of contacting geometry and cross sectional geometry of the microchannels.

Knowledge of pressure drop during two-phase flow in microchannels is also essential for the design of energy efficient systems. There are, however, relatively few studies available on pressure drop in liquid-liquid microchannel flows (e.g. Kashid et al., 2007; Chakrabati et al., 2005; Jovanovic et al. 2011) compared to those available for gas-liquid flows (e.g. Kreutzer et al., 2005; Chen et al., 2002; Triplett et al., 1999; Kawahara et al., 2002). The models which have been developed for the plug liquid-liquid flow pattern in a microchannel are based to two basic contributions, i.e. the hydrodynamic pressure drop of the two individual phases and the pressure drop due to capillary phenomena. Plug flow is usually modelled as a series of unit cells, composed of a dispersed and a continuous phase (Kashid and Agar, 2007; Jovanovic et al., 2011). 
One of the common applications involving the flow of two immiscible liquids is extraction, which is conventionally carried out using organic solvents. Recently, ionic liquids (ILs) have been suggested as alternatives to organic solvents because of their negligible volatility and flammability at common industrial conditions (Freemantle, 2010; Plechkova and Seddon, 2008), which reduce solvent loss and make them inherently safe and environmentally friendly. Ionic liquids can be considered as salts with low melting points (below $100{ }^{\circ} \mathrm{C}$ ) composed exclusively of ions (Freemantle, 2010). Their properties can be tuned by the choice of the anion and/or the cation, allowing them to be optimised for a particular application (Seddon et al., 2000; Stark and Seddon, 2007). The hydrophobicity of the ionic liquids depends both on the alkyl chain length of the associated cation, and on the nature of the anion. Imidazolium ions, especially 1-alkyl-3-methylimidazolium, are often used as the cation. The bis $\{$ (trifluoromethyl)sulfonyl $\}$ amide anion, $\left[\mathrm{N}\left(\mathrm{SO}_{2} \mathrm{CF}_{3}\right)_{2}\right]^{-}$(also known as bistriflamide, and abbreviated to $\left[\mathrm{NTf}_{2}\right]^{-}$), has become a popular anion choice for synthesising hydrophobic ionic liquids, that are chemically and thermally robust (Bônhote et al., 1996).

industry, pharmaceuticals, nuclear reprocessing, etc), there is a perception that the industrial use of ionic liquids is limited by their high costs bringing both real and psychological economic barriers to their wide use (Birdwell et al., 2006; Deetlefs and Seddon, 2006). One approach to circumvent these barriers is by operating within microchannels which require small solvent hold-up. The reduction in solvent volume is compensated by the high efficiencies achieved, because of the thin fluidic films formed in the confined spaces of the small channels, which can significantly reduce mass transfer resistances. Reactions involving ionic liquids have already been tested in microchannels, and yields much higher than in intensely mixed batch processes were found (Pohar et al., 2009). The flow patterns and associated pressure drop of two-phase flows involving ionic liquids are expected to be different to those of common organic solvents, because of their generally high viscosities and their higher densities compared to water.

The present work aims to investigate the flow patterns and the corresponding pressure drops during the flow of an ionic liquid, 1-butyl-3-methylimidazolium bistriflamide $\left(\left[\mathrm{C}_{4} \mathrm{mim}\right]\left[\mathrm{NTf}_{2}\right]\right)$ and de-ionised water in microchannels made from materials that have different wetting characteristics. Moreover, a comparison with existing pressure drop models 
during plug flow was attempted and a modified model was suggested that agreed well with the experimental results. This is the first time that such a study has been presented.

\section{Experimental set-up and procedure}

\subsection{Experimental set-up}

(1)

A schematic of the experimental set up used for the two phase ionic liquid-water flow in microchannels is depicted in Fig. 1. It comprises of three main sections: the fluids delivery section in the mixing zone, the flow visualisation section, and the pressure drop measurement section. Two syringe-pumps (Aladdin-1000, WPI) fed the two liquids to the mixing zone. The pumps were calibrated and the maximum uncertainty of the flowrates was $\pm 2 \%$. Two inlet configurations ( $\mathrm{Y}$ - and T-junction) were used for mixing the fluids, both made of PTFE with all the branches having the same ID $(0.5 \mathrm{~mm})$. In the T-junction, the two fluids entered the mixing zone perpendicularly with the water injected along the test channel axis. The angles of the inlets of the Y-junction were $120^{\circ}$. The test channels used in this work were made of two types of Teflon, PFA and Tefzel, with internal diameter (ID) of $220 \mu \mathrm{m}$ and $270 \mu \mathrm{m}$ respectively, and of borosilicate glass with an internal diameter of $200 \mu \mathrm{m}$. The length (L) of all test channels was $100 \mathrm{~mm}$. The internal diameter of the microchannels was measured using a microscope.

The flow visualisation section comprised a high-speed camera (Phantom Miro 4) connected to a computer for data storage and a light source. Images were acquired at a distance $80 \mathrm{~mm}$ downstream the inlet. For the pressure drop measurements, a differential pressure meter Comark C9555 (range: $0- \pm 200 \mathrm{kPa}$, accuracy $\pm 0.2 \%$ ) was used, connected to two pressure ports before and after the microchannel, as illustrated in Fig. 1. To measure the pressure drop in the glass microchannel, two side channels (referred as t2 in Fig. 1), with a length of $5 \mathrm{~cm}$ each, were added to connect the main channel to the pressure ports. The two Teflon microchannels could be connected directly to the pressure meter, and in this case the side channels $\mathrm{t} 2$ were removed.

An ionic liquid, $\left[\mathrm{C}_{4} \mathrm{mim}\right]\left[\mathrm{NTf}_{2}\right]$, and de-ionised water were used as test fluids. Because the ionic liquid in its pure state absorbs some water, before the experiments started it was stirred with water for $45 \mathrm{~min}$. Saturation with water was confirmed by measuring the viscosities of both pure and saturated ionic liquid with a digital Rheometer DV-III Ultra 
1 (Brookfield). Surface and interfacial tensions of the two liquids were measured with a Kruss

2 DSA 100 drop analyser system by the pendant drop method. The liquid was injected from a 3 needle, and a droplet was formed on the tip of the needle. The droplet was then optically 4 observed, and the surface tension was calculated from the shape of the drop using DSA1 5 software for DSA 100 system. In order to measure the interfacial tension between the two 6 liquids the needle was immersed into water and a droplet of ionic liquid was formed. The 7 properties of the fluids used for the experiments are given in Table 2. The contact angles of the liquids with substrates made from the same materials as the channel walls were also measured using the Kruss DSA 100 system. Both liquid-air-solid and liquid-liquid-solid contact angles were obtained. In the former case a drop of the liquid was placed on top of a flat plate made by borosilicate glass or Teflon in air and the contact angles were found from the still images taken. In the latter case, the plate was immersed in water and the drop of ionic liquid was put on top of it. The measured contact angles are summarised in Table 3.

\subsection{Procedure}

Flow patterns and pressure drop measurements were carried out for different flow rates of the two liquids using both inlets (T- and Y-junction) in all test microchannels. The flow rates of the ionic liquid varied from $0.065 \mathrm{~cm}^{3} \mathrm{~h}^{-1}$ to $11.31 \mathrm{~cm}^{3} \mathrm{~h}^{-1}$, and those of water from $0.0169 \mathrm{~cm}^{3} \mathrm{~h}^{-1}$ to $214.9 \mathrm{~cm}^{3} \mathrm{~h}^{-1}$. The ionic liquid volume fraction varied from 0.05 to 0.8. In all cases, the flow rate of ionic liquid was kept constant and that of water was either increased or decreased. Pressure drop of single phase water and single phase ionic liquid was measured along the microchannels at various flow rates and very good agreement was found with the Hagen-Poiseuille equation. The highest Reynolds numbers are expected for singlephase water flow $\left(\operatorname{Re}_{\text {Water }}\right)$ at superficial velocities the same as the mixture velocity $\left(U_{\text {Mixture }}\right)$ defined below and were up to 540 .

$$
\mathrm{U}_{\text {Mixture }}=\frac{\mathrm{Q}_{\mathrm{IL}}+\mathrm{Q}_{\mathrm{Water}}}{\mathrm{A}}
$$

where $Q_{\mathrm{IL}}$ is the flow rate of ionic liquid, $Q_{\text {Water }}$ is the flow rate of water and $A_{\text {Channel }}$ is the channel cross sectional area.

Initial experiments with the glass capillary showed that the patterns were highly affected by the phase that initially filled the microchannel. The air-liquid-solid and the liquid- 
1 liquid -solid contact angles (Table 3) reveal that none of the two liquids preferentially wets

2 the glass channel wall; in fact the liquid-liquid-solid angle is $\sim 90^{\circ}$. To ensure that water will

3 be the continuous phase, in a typical experiment the channel was filled with the minimum

4 flow rate of water before the required flow rate of the ionic liquid was introduced. When

5 steady state was reached, the pressure drop was measured and the flow configuration was

6 recorded. Subsequently, the flow rate of water was increased stepwise. After a set of

7 experiments was completed, the same procedure was repeated with the next chosen flow rate

8 of ionic liquid. The same experiments were also performed by injecting the water at its

9 maximum flow rate for a particular ionic liquid flow rate and decreasing it stepwise. The flow patterns and pressure drop recorded were the same for both procedures. A few experiments were carried out with the ionic liquid initially filling the channel and indicative results will be discussed.

\section{Results and Discussion}

\subsection{Flow patterns}

It was found that the configuration of the inlet, $\mathrm{T}$ - or $\mathrm{Y}$ - junction, did not affect significantly the flow patterns that were formed or the range they occupied in the flow pattern map. For this reason, only the flow patterns observed with the T-junction will be discussed. In contrast, flow rates, phase volume fraction, and channel wettability had a significant effect on the flow configurations. The main patterns seen in the glass microchannel were plug, plug \& drop 
train, and dispersed flow. In the Teflon microchannels, the main flow patterns observed were annular, plug and drop flow. These patterns could be further subdivided into regimes that have mixed characteristics and appeared usually at the boundaries between the different patterns. The Bond number varied from 0.013 to 0.024 for the 3 microchannels, indicating that gravitational forces have a negligible effect on the formation of the flow patterns.

\subsubsection{Glass microchannel}

As discussed previously, the flow patterns in the glass microchannel are highly affected by the fluid that first fills the channel. In all flow configurations, water is in contact with the channel wall and is always the continuous phase. The different flow configurations obtained are presented in the flow pattern map in Fig. 2 in terms of overall mixture velocity, $U_{\text {Mixture }}$ (Equation 1) against input ionic liquid volume fraction, $\varepsilon_{\mathrm{IL}}$ (Equation 2).

$\varepsilon_{\mathrm{IL}}=\frac{\mathrm{Q}_{\mathrm{IL}}}{\mathrm{Q}_{\mathrm{IL}}+\mathrm{Q}_{\mathrm{Water}}}$

\section{Plug flow}

In this pattern, one liquid forms convex shaped plugs (dispersed phase), with lengths longer than the channel diameter that are separated by slugs of the other liquid (continuous phase), while a thin film of the continuous phase surrounds the dispersed plugs (Fig. 3(a)). In the glass microchannels ionic liquid is flowing as the dispersed phase, while water is the continuous phase. Plug length varied depending on the flow rates. Two types of plugs were seen; short size plugs of $0.2-2 \mathrm{~mm}$ at low ionic liquid volume fractions (0.05-0.25) and elongated plugs $(>2 \mathrm{~mm})$ at high ionic liquid volume fractions (0.5-0.8). In some cases, in agreement with liquid-liquid flow in larger channels, some isolated drops were observed in the slugs between the plugs. As can be seen in Fig. 2, plug flow occupies a large area of the flow pattern map at low and high ionic liquid fractions. At mixture velocities between 0.5$1.0 \mathrm{~m} \mathrm{~s}^{-1}$ and ionic liquid volume fractions lower than 0.13 , the interfacial forces which are responsible for stabilising the shape of the plugs, are overcome by inertia forces and disturbances appeared at the head and tail of the plugs, with undulations forming along the length of the plug (Fig. 3(b)). It was also found that the length of the ionic liquid plugs decreased slightly, and that of the water slugs increased with increasing water flow rate, at a 
constant ionic liquid flow rate. These size variations were more evident at low total flow rates, $U_{\text {Mixture }}<0.01 \mathrm{~m} \mathrm{~s}^{-1}$, and ionic liquid volume fractions $\varepsilon_{\mathrm{IL}}>0.6$ where the plug length varied by $5-10 \%$.

\section{$\underline{\text { Plug \& drop train flow }}$}

The term "plug \& drop train" is used to describe the pattern where ionic liquid plugs of different sizes and drops are flowing together in a row within the water phase, while there is no distinct water slug, Fig. 3(c). This pattern occurred at ionic liquid volume fractions $\varepsilon_{\mathrm{IL}}>0.5$ and high total flow rates. At $U_{\text {Mixture }}>0.013 \mathrm{~m} \mathrm{~s}^{-1}$, the number of plugs increased with increasing ionic liquid fraction and their size was irregular, which led to the formation of this pattern. The low interfacial tension between water and ionic liquid, which favours drop break-up could explain the formation of this pattern. It is worth mentioning that, in this pattern, the ionic liquid could also come in contact with the pipe wall.

\section{Intermittent flow (plugs with drops at tail)}

The intermittent flow regime is characterised by ionic liquid plugs with drops of various sizes at their tails, Fig. 3(d). It is located mainly at ionic liquid volume fractions $0.33<\varepsilon_{\mathrm{IL}}<0.5$ and $U_{\text {Mixture }}>0.001 \mathrm{~m} \mathrm{~s}^{-1}$. This is a transitional pattern between plug and "plug \& drop train" flow, or between plug (at low $\varepsilon_{\mathrm{IL}}$ ) and elongated plug (at high $\varepsilon_{\mathrm{IL}}$ ) flow. With increasing total flow rate, the drops at the tails of the plugs become larger. Moreover, at $U_{\text {Mixture }}>0.012 \mathrm{~m} \mathrm{~s}^{-1}$ with increasing ionic liquid volume fraction, the drops at the tails of the plugs increase in size and eventually break up into smaller ones, which spread in the water slug and can even reach the front of the following plug, establishing the plug \& drop train flow.

\section{Dispersed flow}

The dispersed pattern (ionic liquid as dispersed phase, Fig. 3(e), occurs at very high flow rates $U_{\text {Mixture }}>0.625 \mathrm{~m} \mathrm{~s}^{-1}$ and for low ionic liquid volume fractions, $\varepsilon_{\mathrm{IL}}<0.1$. The small interfacial tension that favours drop break-up contributes to this.

When ionic liquid came in contact with the tube wall, the flow patterns became disturbed. This particularly happened at low total flow rates. In this case, the channel was cleaned and the series of experiments were repeated. A few experiments were also conducted 
with the ionic liquid injected first in the channel instead of water. In this case, ionic liquid became the continuous phase and water was flowing as the dispersed, while the patterns were almost the same as those formed in the Teflon microchannels (see below). For example, throat annular flow with water in the core of the channel (Fig. 3(g)) was detected almost at the same range of mixture velocities. In addition, at high volume fractions, $\varepsilon_{\mathrm{IL}}>0.7$ and high mixture velocities, drop flow was obtained. It is worth mentioning, that the same throat annular flow was not found when water was first injected in the glass microchannel and was the continuous phase. Instead at these conditions plug\& train flow was observed. This can be attributed to the low superficial water flowrates that cannot easily sustain a continuous water film along the channel. In addition when the ionic liquid is the dispersed phase, inertial forces are negligible $\left(\mathrm{We}_{\mathrm{IL}}<<1\right.$ ), and do not lead to the formation of an annulus core. At low ionic liquid flow rates $Q_{\mathrm{IL}}<1.131 \mathrm{~cm}^{3} \mathrm{~h}^{-1}$ and for volume fractions $\varepsilon_{\mathrm{IL}}<0.330$ $\left(U_{\text {Mixture }}<0.030 \mathrm{~m} \mathrm{~s}^{-1}\right)$, plug flow was formed but there was no continuous phase film surrounding the dispersed plugs. In this case, both phases were alternatingly contacting the channel wall. It is possible that at these conditions, the ionic liquid film surrounding the water slugs is very thin and can easily break up allowing the water plugs to come into contact with the channel wall.

\subsubsection{Teflon microchannels}

The flow pattern map obtained with the Teflon microchannels (made from FEP and from Tefzel) can be seen in Fig. 4. The symbols correspond to the FEP microchannel, while the lines correspond to the Tefzel one.

\section{Plug flow}

In the two Teflon microchannels (FEP and Tefzel), as would be expected for hydrophobic channel walls, water forms convex shaped plugs and ionic liquid forms concave slugs; a film of ionic liquid surrounds the water plugs. As can be seen from Fig. 4, plug flow occupies a large area of the flow pattern map for both channels (similar to the glass microchannel). Plug flow is established for a narrower range of mixture velocities and volume fractions for the FEP microchannel compared to the Tefzel one. At low $\varepsilon_{\mathrm{IL}}<0.13$ and $0.006 \mathrm{~m} \mathrm{~s}^{-1}<U_{\text {Mixture }}<0.055 \mathrm{~m} \mathrm{~s}^{-1}$, the plugs in the Tefzel microchannel had irregular sizes. 
It was also found that, for a constant ionic liquid flow rate, an increase in the water

2 flow rate, increased the size of water plugs, while that of the ionic liquid slugs was slightly decreased. At volume fraction 0.5 , it was found that as the mixture velocity increased, the plugs were decreased in size but increased in number due to the rapid penetration of one phase into the other at the inlet, which breaks the water stream into a larger number of segments. In this way, a high specific interfacial area is achieved that can improve mass transfer rates.

$\underline{\text { Annular flow }}$

In annular flow, the lighter of the two phases (water) flows in the centre of the channel (core flow), while the heavier one (ionic liquid) is contained in a thin film wetting the channel wall. Annular flow occurs at high velocities of the water phase, where the inertia of the water is sufficiently high to break through the ionic liquid in slug flow. Depending on mixture velocity and ionic liquid volume fraction different kinds of annular flow, namely quasi, throat and rivulet, were observed (Fig. 3).

In the FEP microchannel, annular flow exists at ionic liquid volume fractions from 0.05 to 0.2 and mixture velocities from $0.006 \mathrm{~m} \mathrm{~s}^{-1}$ to $1.653 \mathrm{~m} \mathrm{~s}^{-1}$. At $U_{\text {Mixture from }}$ $0.006 \mathrm{~m} \mathrm{~s}^{-1}$ to $0.063 \mathrm{~m} \mathrm{~s}^{-1}$, the elongated plugs of water coalesce with each other and create a core, Fig. 3(f). At higher mixture velocities $0.082 \mathrm{~m} \mathrm{~s}^{-1}<U_{\text {Mixture }}<0.330 \mathrm{~m} \mathrm{~s}^{-1}$, throat annular flow was observed, Fig. 3(g). In the Tefzel microchannel, quasi annular flow was not seen, and the throat annular flow was slightly shifted to lower ionic liquid volume fractions and higher mixture velocities compared to the FEP one. In both types of channels, at high $U_{\text {Mixture }}>0.330 \mathrm{~m} \mathrm{~s}^{-1}$ and ionic liquid volume fraction $\varepsilon_{\mathrm{IL}}<0.13$, there is a large velocity difference between the two phases and the interface becomes irregular, leading to the rivulet annular flow, Fig. 3(h), with the core occasionally coming in contact with the channel wall.

Drop flow

The term drop flow, Fig. 3(i), is used to describe a pattern where water drops, with sizes smaller than the channel diameter, are flowing in a row in the channel. This pattern is seen mainly at relatively high mixture velocities and ionic liquid volume fractions, as can be seen in Fig. 4.

Irregular flow 
Irregular flow, Fig. 3(j), was detected only at high mixture velocities for both microchannels and represents a transition between plug and annular flow.

\subsection{Comparison of flow pattern boundaries in the 3 test sections}

The flow pattern boundaries observed in the three different test sections used in this work are compared in Fig. 5. The patterns and their boundaries are similar in the two Teflon microchannels. In the Tefzel channel, the plug flow occupies a slightly larger area of the map compared to the FEP channel, and the boundary to annular flow is shifted to higher mixture velocities and lower ionic liquid volume fractions, while the boundary to drop flow is shifted to slightly higher mixture velocities and ionic liquid volume fractions. Finally, the irregular flow was observed at almost the same mixture velocities in both microchannels, but at lower ionic liquid volume fractions (higher Re numbers of the dispersed water phase) in the Tefzel channel compared to the FEP one. These differences in flow pattern boundaries are attributed to the small differences in the inner diameter between the FEP (ID=220 $\mu \mathrm{m})$ and Tefzel $(\mathrm{ID}=270 \mu \mathrm{m})$ channels, which is in agreement with previous findings (Kashid et al., 2005). In contrast, in the glass microchannel with water as the continuous phase, annular and drop flow were not detected. Instead of annular flow, at low ionic liquid volume fractions and high mixture velocities, dispersed flow appeared, while instead of drop flow at high ionic liquid volume fractions, plug \& drop train flow occurred. The largest area of the map was occupied by some type of plug flow, divided into plug, intermittent and "elongated plug" flow.

The flow pattern boundaries were compared against the criteria by Kashid and KiwiMinsker (2011). It should be noted here that these criteria had been tested against results from low viscosity oils. As a result the $\mathrm{Re}_{\mathrm{C}} / \mathrm{Ca}_{\mathrm{C}}$ numbers where higher compared to those from the present study. According to the criteria, the patterns in the glass capillary with water as the continuous phase should all be in the surface tension dominated region $\left(\operatorname{Re}_{\mathrm{D}} \mathrm{d}_{\mathrm{ch}} / \varepsilon_{\mathrm{D}}<0.1 \mathrm{~m}\right)$. This agrees with the experimental observations since no annular flow was found. For the two Teflon microchannels (mainly for the FEP one, with $\mathrm{ID}=220 \mu \mathrm{m}$ ) plug flow was correctly predicted to fall within the surface tension dominated region $\left(\operatorname{Re}_{\mathrm{D}} \mathrm{d}_{\mathrm{ch}} / \varepsilon_{\mathrm{D}}<0.1 \mathrm{~m}\right)$. However, annular flow was predicted to be in the transition $\left(0.1 \mathrm{~m}<\operatorname{Re}_{\mathrm{D}} \mathrm{d}_{\mathrm{ch}} / \varepsilon_{\mathrm{D}}<0.35 \mathrm{~m}\right)$ rather than the inertia region $\left(\operatorname{Re}_{\mathrm{D}} \mathrm{d}_{\mathrm{ch}} / \varepsilon_{\mathrm{D}}>0.35 \mathrm{~m}\right)$. Similar disagreement was found between the model predictions and the experimental results of Salim et al. (2008) who used a highly viscous 
continuous phase as in the current study resulting in low $\mathrm{Re}_{\mathrm{C}} / \mathrm{Ca}_{\mathrm{C}}$ numbers; in their case a stratified flow inertia regime, was predicted to be within the transition region.

\subsection{Plug length measurements}

Plug lengths (of water) were measured in the two Teflon microchannels only for the T-junction as inlet, for equal flow rates of the two liquids, using the high-resolution images recorded. The average lengths (over 10 measurements per case) had a deviation of around $\pm 6 \%$ from the mean value. The data are plotted in Fig. 6 as ratio of plug length over channel diameter versus flow rate of water. As can be seen, in both microchannels the water plug length becomes shorter as the water flow rate increases. This means that the interfacial area increases slowly with increasing flow rate. In addition, the dimensionless plug length is longer in the Tefzel compared to the FEP channel, which means that in the slightly larger Tefzel channel longer plugs formed for the same flow conditions. Interfacial area is therefore increased in the channel with the smallest dimension (FEP).

\subsection{Pressure drop}

The pressure drop $(\Delta P)$ across a given length of microchannel $(100 \mathrm{~mm})$ was measured for different flow rates of both phases and various ionic liquid volume fractions, $\varepsilon_{\mathrm{IL}}$. The data obtained in this work are presented in Figs. 7-9 against input ionic liquid volume fraction for constant ionic liquid flow rates. The pressure drop of the single-phase ionic liquid $\left(\varepsilon_{\mathrm{IL}}=1\right)$, having the same flow rate as the ionic liquid phase in the two-phase mixture, was also measured and presented. For the two Teflon microchannels, the relevant flow patterns established are also shown, while for the glass microchannel pressure drop was only measured during plug flow.

\subsubsection{Teflon microchannels}

The pressure drop results for the two Teflon microchannels can be seen in Figs. 7 and 8 for the FEP and the Tefzel materials respectively. Pressure drop was measured at least seven times for each set of conditions, and the mean values were calculated. The deviation from the mean value was very low (on average below $\pm 4 \%$ ) for all cases (the standard 
deviation lines cannot be seen in the graphs because they are smaller than the symbols), apart from high mixture velocities and low ionic liquid volume fractions where the deviation was between $5.5-12 \%$.

In the FEP channel, pressure gradients are very similar for both the $\mathrm{T}$ - and $\mathrm{Y}$ - junction inlets used, Figs. 7(a) and 7(b). As expected at a constant flow rate of ionic liquid, an increase in the water flow rate (decrease in the ionic liquid volume fraction) led to an increase in the measured pressure drop, because the mixture flow rate increased. At higher ionic liquid flowrates the increase became more prominent when annular flow established. When the pattern changes from plug to annular for the same ionic liquid flowrate, the ionic liquid is restricted to a smaller part of the cross section and its velocity will be increased resulting in higher frictional pressure drop. Interestingly, at ionic liquid flow rate of $5.655 \mathrm{~cm}^{3} \mathrm{~h}^{-1}$ and at low ionic liquid volume fractions, this trend is reversed and a decrease in the two-phase pressure drop was observed. This happens during annular flow when the pattern changes from throat to rivulet annular and water, that has a lubricating effect, comes in contact with the channel wall. In the case of $Q_{\mathrm{IL}}=8.483 \mathrm{~cm}^{3} \mathrm{~h}^{-1}$, the pressure drop at low ionic liquid volume fractions was not measured because it was outside the range of the pressure meter used.

Similar results for both inlets were also found in the Tefzel channel and are presented in Fig. 8 for the T-junction. Pressure drop increases with increasing water flow rate, similar to the FEP microchannel. This increase is more profound at ionic liquid flow rates higher than $5.655 \mathrm{~cm}^{3} \mathrm{~h}^{-1}$.

\subsubsection{Glass microchannel}

In the glass microchannel, pressure drops were measured only for ionic liquid volume fractions between 0.05-0.42 where short plugs were detected. As found for the Teflon microchannels, the pressure drop is similar for both inlet configurations and increases with increasing water flow rate (Fig. 9 for the T-junction). However, in the glass microchannel, the pressure drop of single phase flow ionic liquid at the same flow rate as in the mixture is always higher than the pressure drop of the two-phase mixture. This is because, in the glass microchannel, the phase in contact with the channel wall is the low viscosity water. High values of pressure drop, approaching those of single-phase water, were obtained at flow rates $Q_{\mathrm{IL}}>5.655 \mathrm{~cm}^{3} \mathrm{~h}^{-1}$ and low $\varepsilon_{\mathrm{IL}}$, but were still less than those of single-phase ionic liquid. In 
the case of the glass microchannel, the deviation from the mean value was in all cases very low. These findings are very important because they demonstrate that the high viscosities of the ionic liquids are not limiting factors for their use in small channels, provided suitable flow patterns are established.

Some indicative experiments were performed in the glass microchannel when the ionic liquid was the continuous phase. In this case, pressure drop was found to be higher than that of single phase ionic liquid as is the case for the two Teflon microchannels.

\subsection{Comparison of the pressure drop for the 3 test sections}

The pressure drops for the three different microchannels are compared in Fig. 10 for a constant ionic liquid flow rate of $Q_{\mathrm{IL}}=2.262 \mathrm{~cm}^{3} \mathrm{~h}^{-1}$. Because of the small differences in the diameters of the three channels, to enable the comparisons the data have been nondimensionalised by dividing the two-phase pressure drop with that of the ionic liquid flowing alone in the channel $(\eta)$. As can be seen in Fig. 10, the dimensionless pressure drop $(\eta)$ in the two Teflon microchannels is higher than in glass. This can be explained by the fact that in the two Teflon microchannels, the continuous phase is the ionic liquid which has higher viscosity and, therefore, causes higher frictional pressure drop than water which is the continuous phase in the glass microchannel. It was also observed that, in all cases, $\eta$ decreases as the ionic liquid volume fraction increases. This decrease is more obvious at low $\varepsilon_{\mathrm{IL}}<0.25$.

In the case of the two Teflon microchannels, it is seen that the dimensionless pressure drop for the FEP channel is higher over the whole range of ionic liquid volume fractions studied. During plug flow $\left(\varepsilon_{\mathrm{IL}}>0.25\right)$, this difference is attributed to the number of slugs present. As was discussed in Section 3.3, compared to the FEP channel, under the same phase flow rates longer plugs are formed in the Tefzel channel, and their number is reduced; this will result in a lower capillary pressure drop contribution to the overall pressure drop (Jovanovic et al., 2011). At lower ionic liquid volume fractions $\left(\varepsilon_{\mathrm{IL}}<0.25\right)$, the difference of the dimensionless pressure drop between the two Teflon microchannels is higher. In the FEP channel, annular flow starts just below $\varepsilon_{\mathrm{IL}}<0.25$, explaining the increase in pressure drop at this volume fraction. In the Tefzel channel, the flow remains plug until $\varepsilon_{\mathrm{IL}}=0.1$, where it becomes irregular (with both plug and annular flow characteristics); annular flow establishes only at $\varepsilon_{\mathrm{IL}}<0.08$ where the increase in pressure drop is seen. 


\subsection{Comparison with pressure drop models}

The drop measurements during plug flow in the Tefzel microchannel are compared with the existing models of Kashid and Agar (2007b) and Jovanovic et al. (2011). As was mentioned before, in the Tefzel channel ionic liquid was the continuous phase that formed a film around the dispersed water plugs. In both works, plug flow is considered as a series of unit cells, alternatingly occupied by each phase. Kashid and Agar (2007b) do not consider the film that surrounds the plugs and suggest that pressure drop is equal to the frictional pressure drop of the dispersed and of the continuous phases, and of the interfacial pressure drop (Eq. $3)$.

$$
\Delta \mathrm{P}_{\text {plug flow }}=\Delta \mathrm{P}_{\text {Frictional }}+\Delta \mathrm{P}_{\text {Interfacial }}=\left(\Delta \mathrm{P}_{\mathrm{Fr}, \mathrm{c}}+\Delta \mathrm{P}_{\mathrm{Fr}, \mathrm{d}}\right)+\Delta \mathrm{P}_{\mathrm{I}}
$$

The frictional pressure drop is calculated from the Hagen-Poiseuille equation, while the interfacial pressure drop from the Young-Laplace equation. The predictions of this model are compared against the experimental data from this work in Fig. 11. The interfacial pressure drop was calculated using the measured static liquid-liquid-solid contact angles. Agreement is found only at low mixture velocities. At these velocities where the ionic liquid film is very thin and expected to be almost stagnant, the contribution of the dispersed water phase seems to be predicted correctly. At higher velocities and higher $\mathrm{Ca}$ numbers, however, the ionic liquid film thickness increases and would have some velocity, causing additional frictional pressure drop. Since the model assumes that the less viscous water comes in contact with the wall periodically, it underestimates the frictional pressure drop in the slug part of the flow which should depend on the combination of ionic liquid wall and interfacial shear stresses. In addition, as We number increases the interfacial forces become week and the plugs cannot maintain their shape; the front part elongates whilst the back end flattens (Dore et al., 2012). This leads to deviations from the pressure drop calculated for a static contact angle.

In their model Jovanovic et al. (2011) included the film around the slugs. They found that the influence of the film velocity on the plug pressure drop is negligible (lower than $1.4 \%$ ) and suggested the following equation for stagnant film

$$
\Delta \mathrm{P}_{\text {plug flow }}=\frac{8 \mathrm{U}_{\text {slug }} \mu_{\mathrm{d}} \mathrm{aL}}{\left(\mathrm{R}-\mathrm{h}_{\text {film }}\right)^{2}}+\frac{8 \mathrm{U}_{\text {mix }} \mu_{\mathrm{c}}(1-\mathrm{a}) \mathrm{L}}{\mathrm{R}^{2}}+\frac{\mathrm{L}}{\mathrm{l}_{\mathrm{u}}} \mathrm{C}(3 \mathrm{Ca})^{2 / 3} \frac{\mathrm{T}}{\mathrm{d}}
$$


2 The film thickness was estimated using Bretherton's equation (Bretherton, 1961)

3

$4 \mathrm{~h}_{\text {film }}=1.34 \mathrm{RCa}^{2 / 3}$

5

6

whilst in systems, where the continuous phase has a considerably higher viscosity that the dispersed phase a correction factor of $2^{2 / 3}$ was applied (Bico and Quere, 2000). For semispherical plug caps, the constant $\mathrm{C}$, which accounts for the influence of the interface curvature, was found to be 7.16 (Bretherton, 1961).

The comparisons between experimental pressure drop data during plug flow in the Tefzel microchannel and the stagnant film model (Eq. 5) are shown in Fig. 12. Good agreement was only found at low flow rates. Bretherton's equation for film thickness (corrected by the factor proposed by Bico and Quere, 2000) that was used in the Jovanovic equation is not valid for high capillary numbers and film thickness larger than $1 \%$ of the channel radius. Clearly film thickness has an important effect on pressure drop. Previously we had reported that current correlations are not able to predict the film thicknesses in ionicliquid water flow in microchannels and suggested a new correlation (Dore et al, 2012), given by

As can be seen in Fig. 13, pressure drops predicted using the film thickness calculated by equation (6) agree very well with the experimental data (mean relative error $\sim 8 \%$ ). The new model was able to predict pressure drop during plug flow in all channels tested within $14 \%$.

\section{Conclusions}

The flow patterns and pressure drop of the two-phase flow of a hydrophobic ionic liquid $\left[\mathrm{C}_{4} \mathrm{mim}\right]\left[\mathrm{NTf}_{2}\right]$ and de-ionised water were investigated in capillaries. For the experiments, three different test section materials were used, two types of Teflon (FEP and Tefzel) that are both preferentially wetted by the ionic liquid, and glass that is similarly wetted by both phases. 
In all cases studied, the inlet configuration ( $\mathrm{T}$ - or $\mathrm{Y}$ - junction) did not affect the flow patterns or pressure drop. In the glass microchannel, the patterns were highly affected by the phase that initially filled the channel. The main flow patterns observed were plug flow with ionic liquid plugs, intermittent flow with ionic liquid drops at the tail of the plug, and "plug \& drop train" flow where ionic liquid plugs and drops were flowing together in a row along the microchannel within a water continuous phase. In the two Teflon microchannels, the main flow patterns were annular (water in core) at low ionic liquid volume fractions, with plug and drop flow (with water plugs in both cases). In addition, plug length measurements in the Teflon microchannels showed that plug length decreases with increasing total flow rate.

Pressure drop in the Teflon microchannels, at a constant ionic liquid flow rate, was found to increase as the ionic liquid volume fraction decreased and was always higher than the single phase ionic liquid value at the same flow rate as in the two-phase mixture. At high ionic liquid flow rates and low $\varepsilon_{\mathrm{IL}}(<0.13)$, a larger increase in pressure drop was seen which was attributed to the change in the pattern from plug to annular. This was followed by a decrease in pressure drop when the pattern changed from throat to rivulet annular flow. Differences in the pressure drops between the two Teflon microchannels during plug flow were attributed to different plug lengths. In the glass microchannel during plug flow with the water as the continuous phase, pressure drop for a constant ionic liquid flow rate was always significantly lower than the single phase ionic liquid value at the same flow rate as in the mixture velocity. The pressure drop was, however affected by the phase which initially filled the channel. It was also found that when an improved correlation for film thickness was used in a plug flow pressure drop model, there was very good agreement with the experimental results.

\section{References}

Angeli P., Hewitt G.F., 2000. Flow structure in horizontal oil-water flow. Int. J. Mul. Fl., 22, $7,1117-1140$

Angeli P., Gavriilidis A., 2008.Hydrodynamics of Taylor flow in small channels: a review. Proc. Inst. Mech. Eng. Part C, J. Mech. Eng. Sci. 222 (5), 737-751.

Birdwell J.F., McFarlane J., Hunt R.D., Luo H., DePaoli D.W., 2006. Separation of ionic liquid dispersions in centrifugal solvent extraction contactors. Sep. Sci. Technol. 41, 22052223. 
1 Bônhote, P., Dias, A.P., Papageorgiou, N., Kalyanasundaram, K., Grätzel, M. 1996.

2 Hydrophobic, highly conductive ambient-temperature molten salts. Inorg. Chem. 35, 116831178.

4 Brauner N., Maron D.M., 1992. Stability analysis of stratified liquid-liquid flow. Int. J.

5 Multiphase Flow, Vol. 18, No. 1, 103-121

6 Bretherton F.P., 1961. The motion of long bubbles in tubes. J. Fluid Mech. 10, 166-168.

7 Chakrabati D.P., Das G., Ray S., 2005. Pressure drop in liquid-liquid two phase horizontal

8 flow: experiment and prediction. Chem. Eng. Technol. 28, No 9.

9 Chen I.Y., Yang K.S., Wang C.C., 2002. An empirical correlation for two-phase frictional performance in small diameter tubes. Int. J. Heat Mass Transfer 45, 3667-3671.

Deetlefs, M., Seddon, K.R., 2006. Ionic liquids: fact and fiction, Chim Oggi - Chem. Today 24 [Mar-Apr], 16-23.

Dessimoz A., Cavin L., Renken A., Kiwi-Minsker L., 2008. Liquid-liquid two-phase flow patterns and mass transfer characteristics in rectangular glass microreactors. Chem. Eng. Sci. 63, 4035-4044.

Dummann G., Quittmann U., Groschel, Agar David W., Worz O., Morgenschweis K., 2003. The capillary-microreactor: a new reactor concept for the intensification of heat and mass transfer in liquid-liquid reactions. Catal. Today 79-80, 433-439.

Foroughi H., Kawaji M., 2011. Viscous oil-water flows in a microchannels initially saturated with oil: Flow patterns and pressure drop characteristics. Int. J. Multiphase Flow, 37, 11471155 .

Freemantle, M., 2010. An Introduction to Ionic Liquids. RSC Publications, Cambridge, UK. Garstecki P., Fuerstman M.J., Stonec H.A., Whitesides G.M., 2006. Formation of droplets and bubbles in a microfluidic T-junction-scaling and mechanism break-up. Lab Chip 6, 437446.

Jovanovic J., Zhou W., Rebrov E.V., Nijhuis T.A., Hessel V., Schouten J.C., 2011. Liquidliquid slug flow: Hydrodynamics and pressure drop. Chem. Eng. Sci. 66, 42-54.

Kashid M.N, Gerlach I., Goetz S., Franzke J., Acker J.F., Platte F., Agar D.W., Turek S., 2005. Internal circulation within the liquid slugs of a liquid-liquid slug-flow capillary microreactor. Ind. Eng. Chem. Res. 44, 5003-5010. alternative to suspended drop or film contactors. Ind. Eng. Chem. Res. 46, 8420-8430. 
1 Kashid M.N, Agar D.W., 2007. Hydrodynamics of liquid-liquid slug flow capillary

2 microreactor: flow regimes, slug size and pressure drop. Chem. Eng. J. 131, 1-13.

3 Kashid M.N., Kiwi-Minsker L., 2011. Quantitative prediction of flow patterns in liquid-liquid

4 flow in microcapillaries. Chem. Eng. Proc., 50, 972-978

5 Kawahara A., Chung P.M.Y., Kawaji M., 2002. Investigation of two phase flow pattern, void

6 fraction and pressure drop in a microchannel. Int. J. Multiphase Flow 28, 1411-1435.

7 Kreutzer M.T., Kapteijn F., Moulijin J.A., Heiszwolf J.J., 2005. Multiphase monolith

8 reactors: chemical reaction engineering of segmented flow in microchannels. Chem. Eng. Sci. $960,5895-5916$.

Lin R., Tavlarides, L.L., 2009. Flow patterns of $n$-hexadecane- $\mathrm{CO}_{2}$ liquid-liquid two-phase flow in vertical pipes under high pressure. Int. J. Multiphase Flow 30, 225-236.

Plechkova, N.V., Seddon, K.R., 2008. Applications of ionic liquids in the chemical industry. Chem. Soc. Rev. 37, 123-150.

Pohar A., Plazl I., Plazl P.Z., 2009. Lipase-catalyzed synthesis of isoamyl acetate in an ionic liquid/n-heptane two-phase system at the microreactor scale. Lab Chip 9, 3385-3390.

Salim A., Fourar M., Pironon J., Sausse J., 2008. Oil-water two-phase flow in microchannels: flow patterns and pressure drop measurements. Can. J. Chem. Eng. 86, 978-988.

Seddon, K.R., Stark, A., Torres, M.J., 2000. Influence of chloride, water and organic solvents on the physical properties of ionic liquids. Pure Appl. Chem. 72, 2275-2287.

Stark, A., Seddon, K.R., 2007. Ionic Liquids, in Kirk-Othmer Encyclopaedia of Chemical Technology, $5^{\text {th }}$ Edit., Ed. Seidel, A., Vol. 26. John Wiley \& Sons, Inc., Hoboken, New Jersey, 836-920.

Triplett K.A., Ghiaasiaan S.M., Abdel-Khalik S.I., LeMouel A., McCord B.N. Gas-Liquid two-phase flow in microchannels, Part II: void fraction and pressure drop. Int. Multiphase Flow 25, 395-410.

Wegmann A., von Rohr P.R., 2006. Two-phase liquid-liquid flows in pipes of small diameters. Int. J. Multiphase Flow 32, 1017-1028.

Zhao Y., Chen G., Yuan Q., 2006. Liquid-liquid two-phase flow patterns in a rectangular microchannel. A.1.Ch.E Journal 52, 4052-4060. 


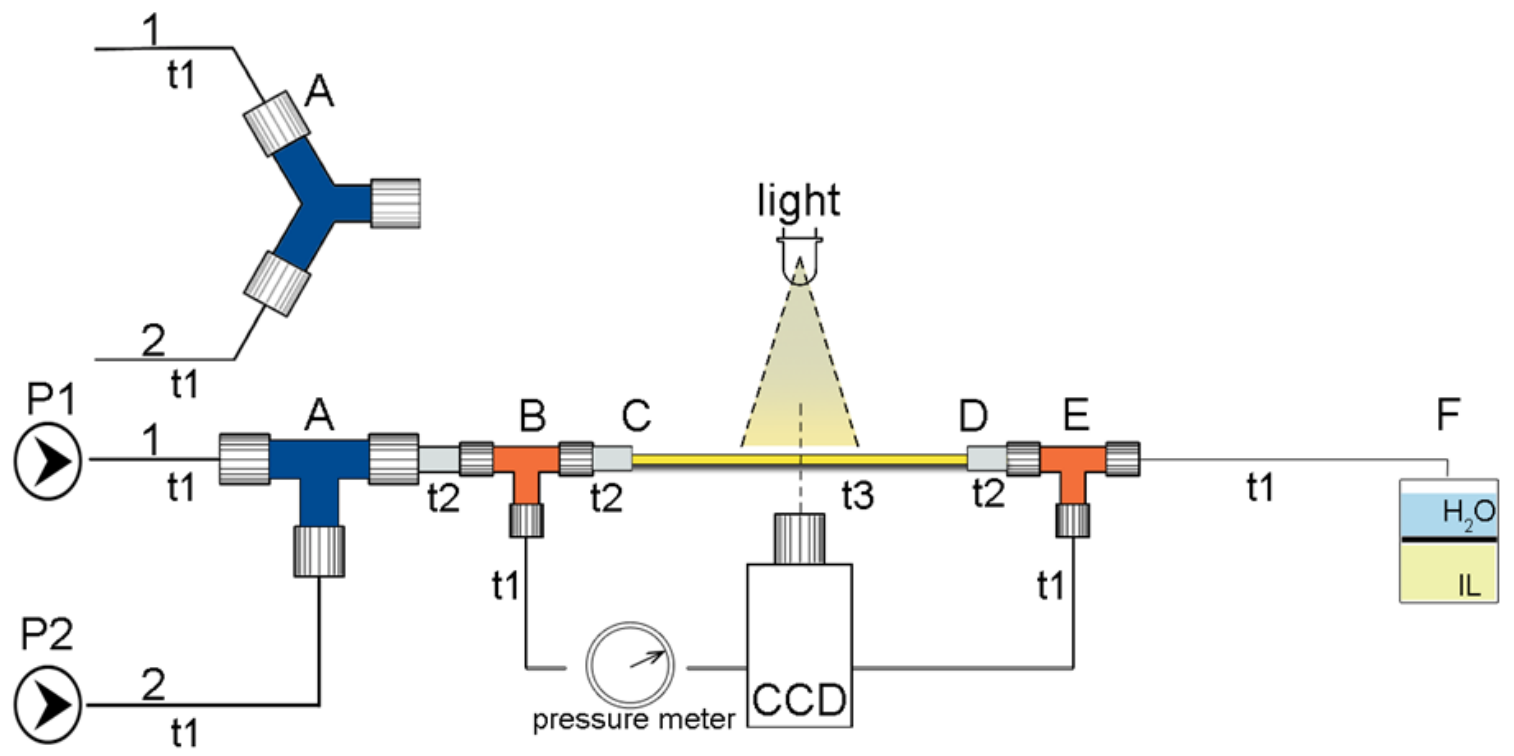

2
A: mixing zone
1: water line
BC: $5 \mathrm{~cm}$
t1: $0.5 \mathrm{~mm}$ ID PTFE (round)
B, E: pressure port
2: ionic liquid line
$\mathrm{CD}: 10 \mathrm{~cm}$
t2: $0.5 \mathrm{~mm}$ ID steel (round)
F: outlet gravity flask
DE: $5 \mathrm{~cm}$
t3: test section (round)

P1, P2: syringe-pump

3 Fig. 1. Schematic of the experimental set-up.

4 
1

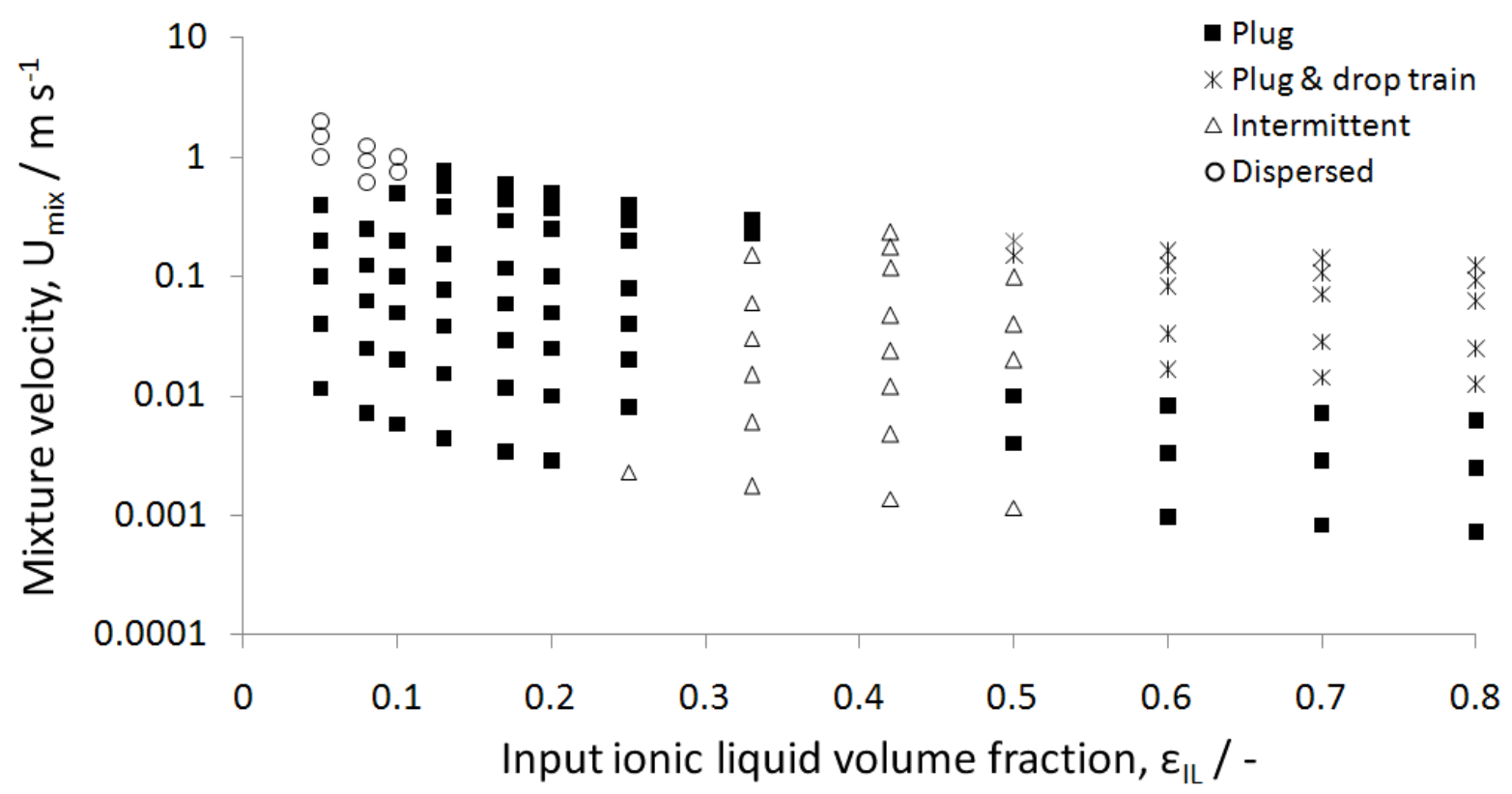

Fig. 2. Ionic liquid-water flow patterns in the glass microchannel with a T-junction inlet 4 


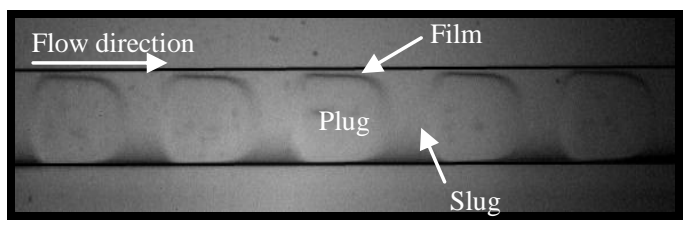

(a) Plug flow

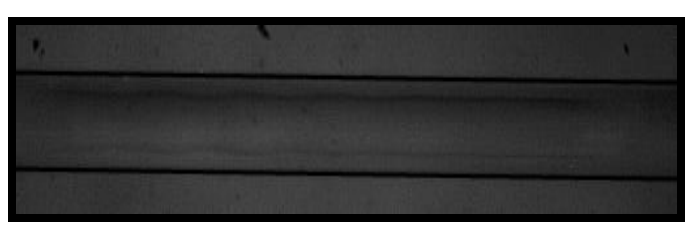

(b) Disturbed plug

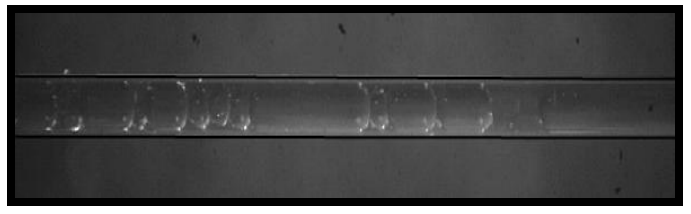

(c) Plug \& drop train flow

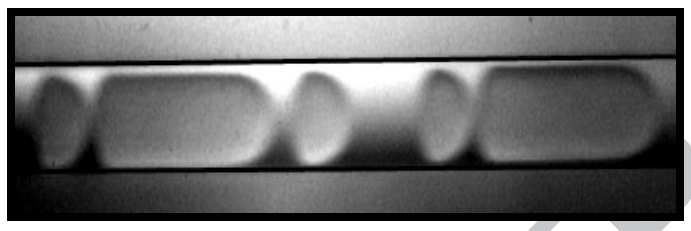

(d) Intermittent flow

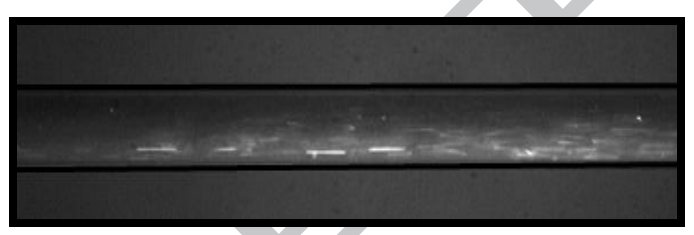

(e) Dispersed flow

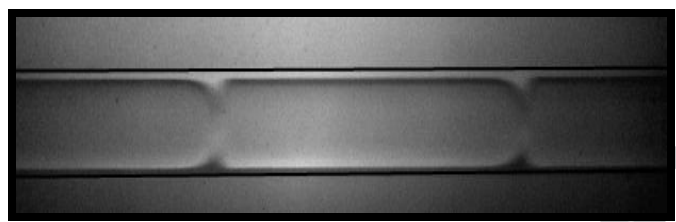

(f) Quasi annular flow

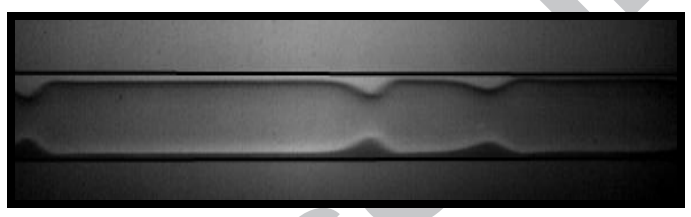

(g) Throat annular flow

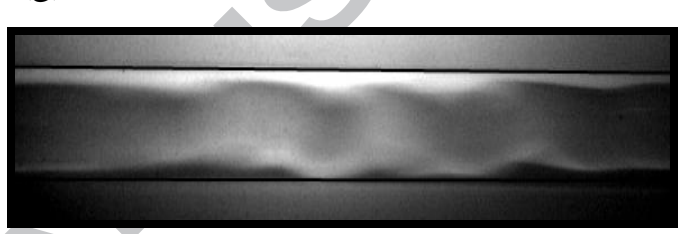

(h) Rivulet annular flow

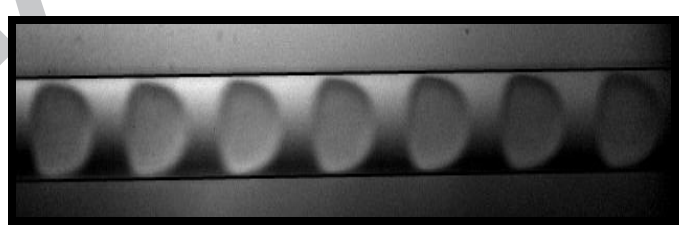

(i) Drop flow

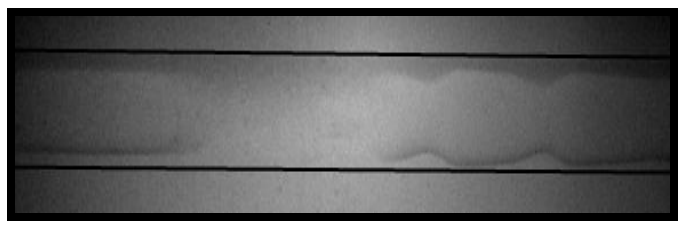

(j) Irregular flow

Fig 3. Photographs of ionic liquid-water two-phase flow patterns in microchannels for various mixture velocities and phase volume fractions. 


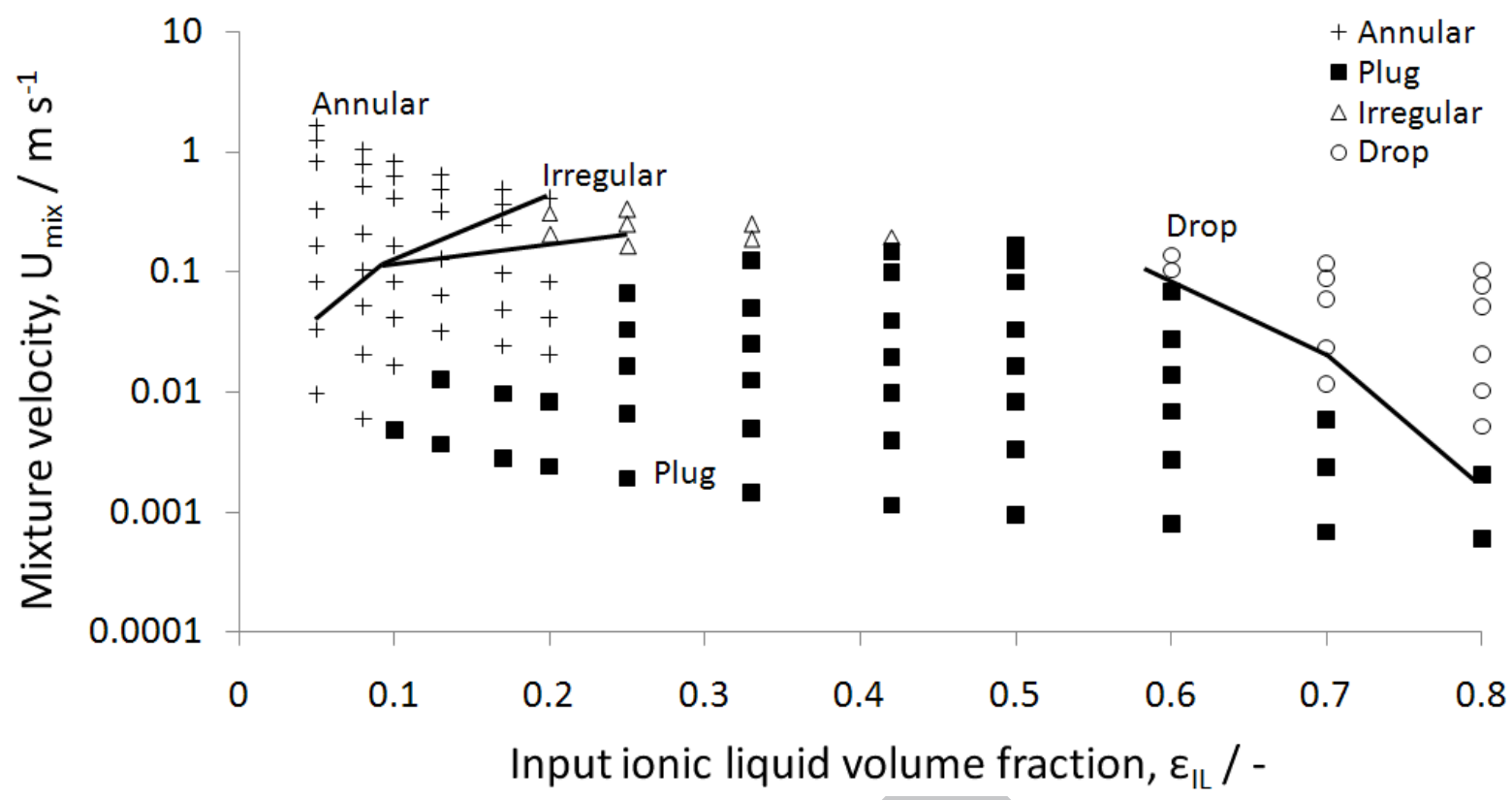

Fig. 4. Ionic liquid-water flow patterns in the two Teflon, FEP and Tefzel, microchannels with a T-junction inlet. FEP: symbols, Tefzel: lines. 


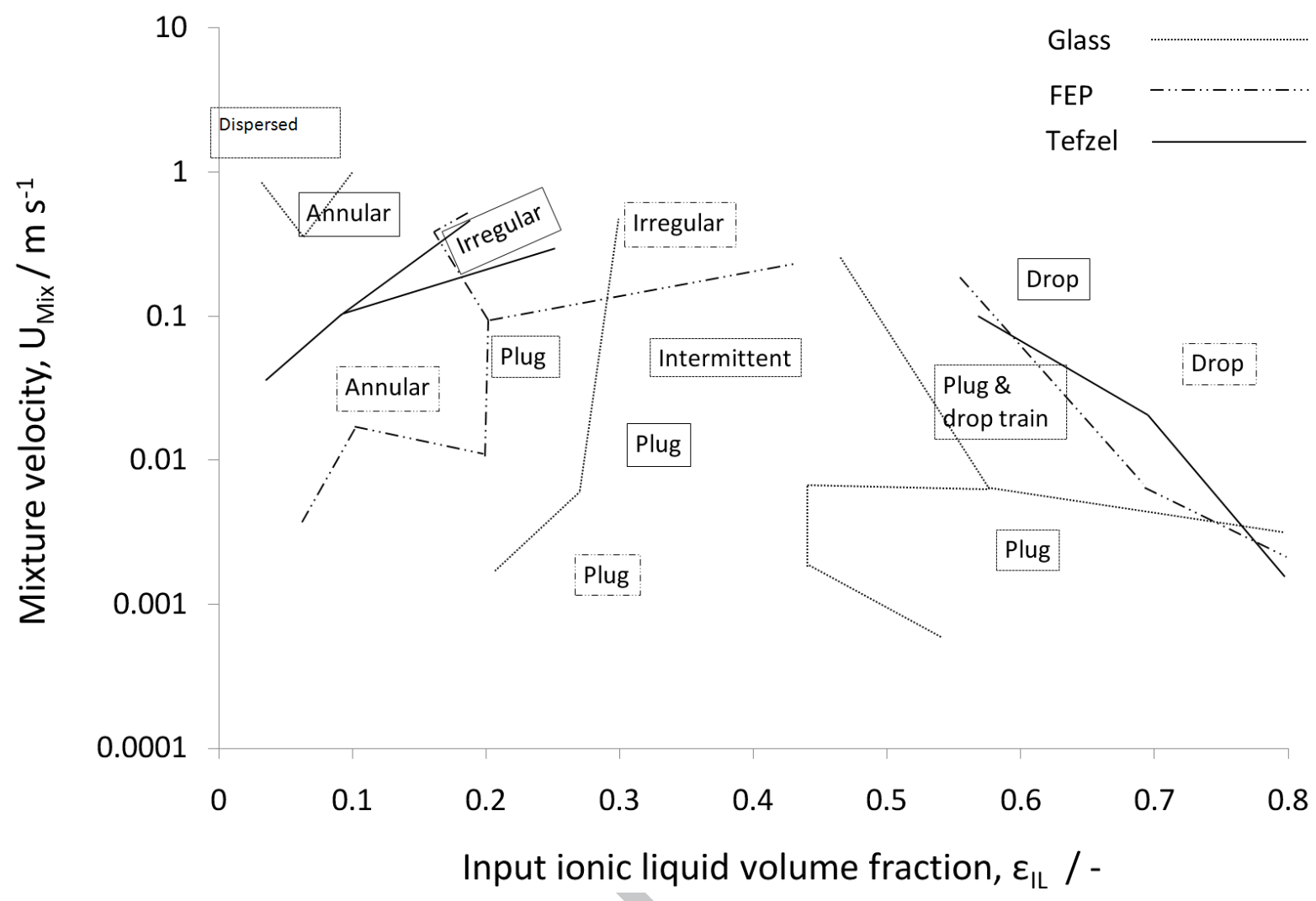

Fig. 5. Comparison of the flow pattern boundaries in the FEP, Tefzel and glass microchannels with a T-junction as inlet. 


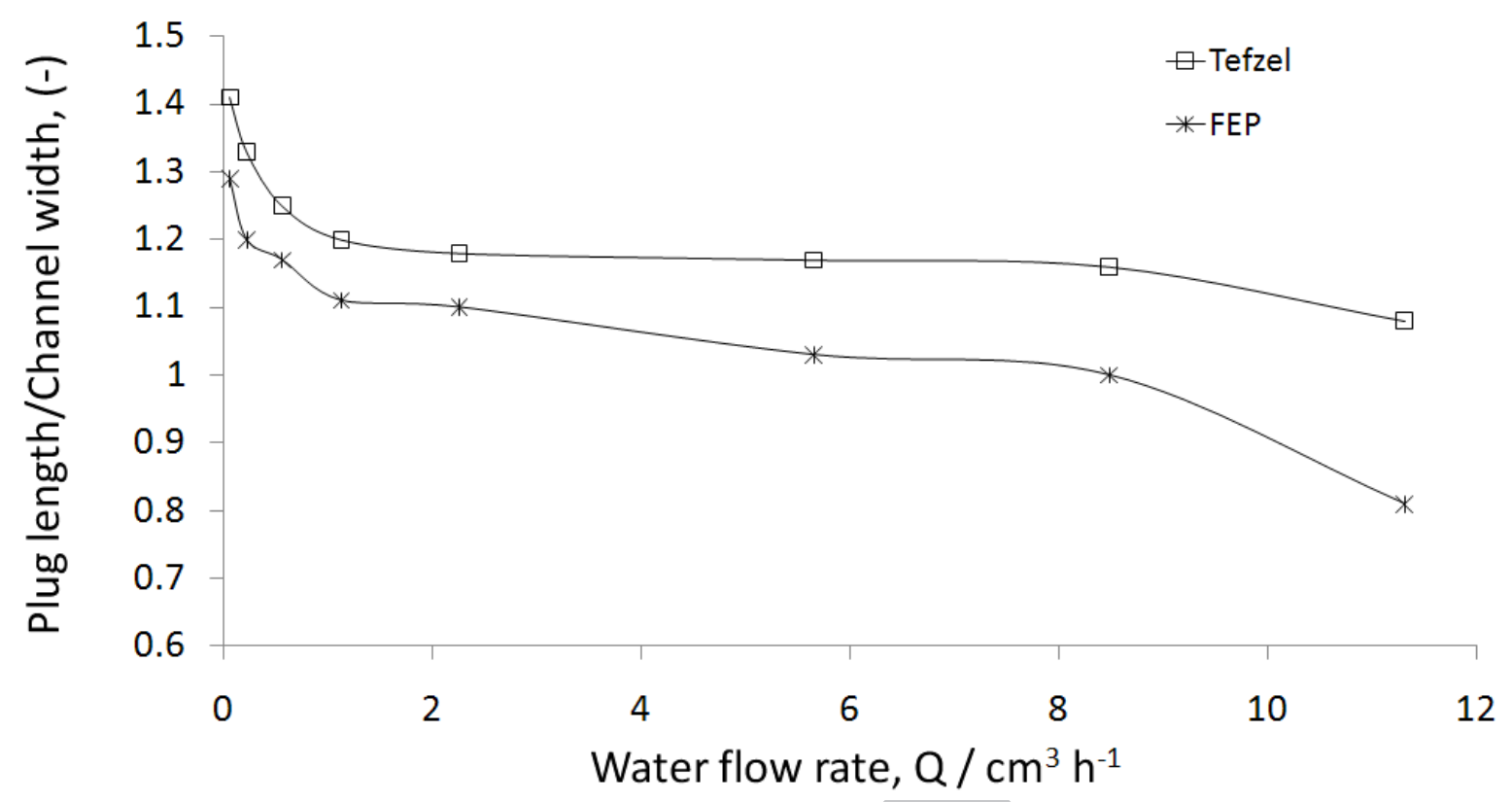

Fig. 6. Average water plug length to channel diameter ratio versus water flow rate in the two Teflon microchannels with a T-junction as inlet for equal water and ionic liquid flow rates. 


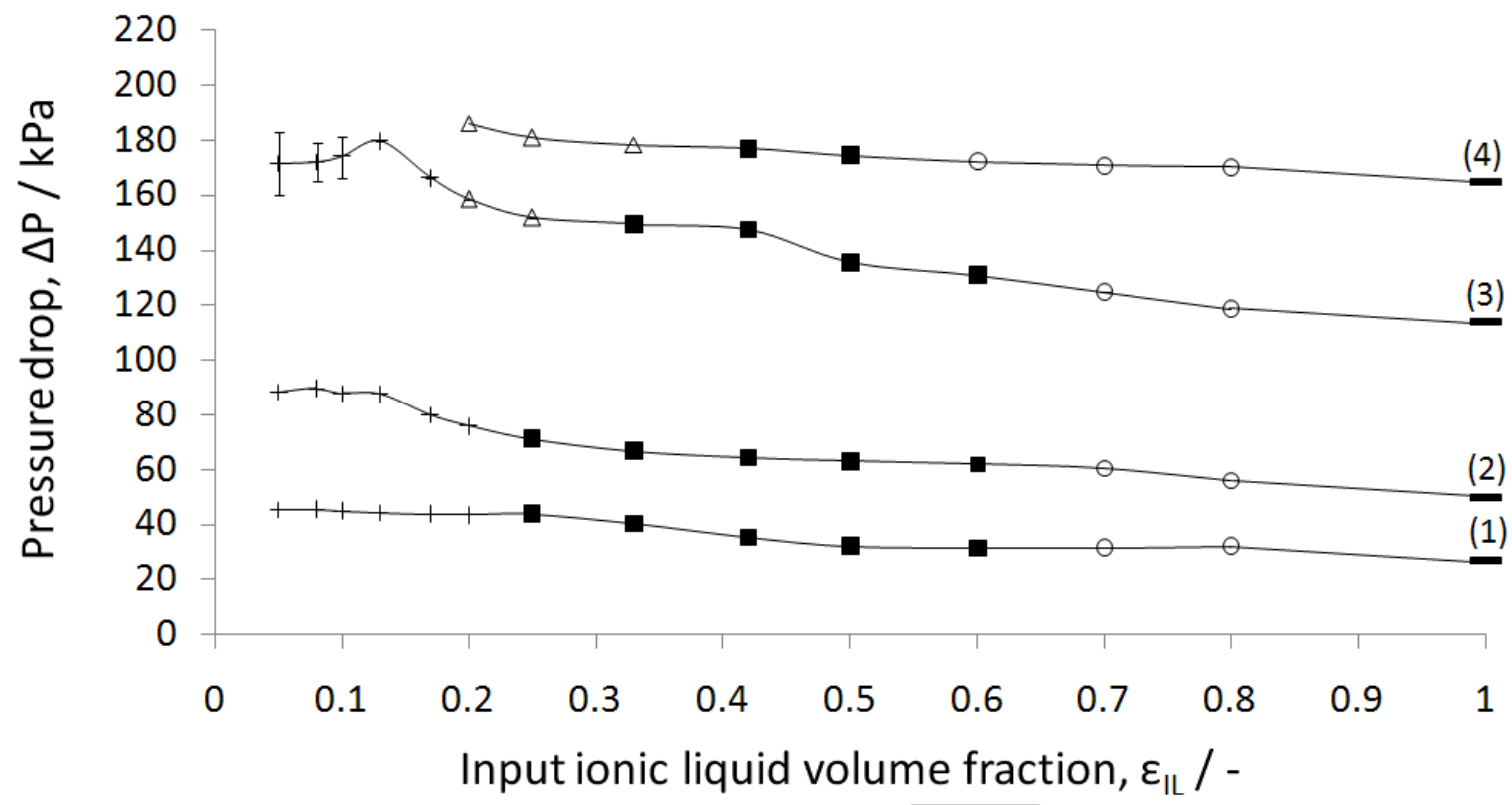

(a) T- junction

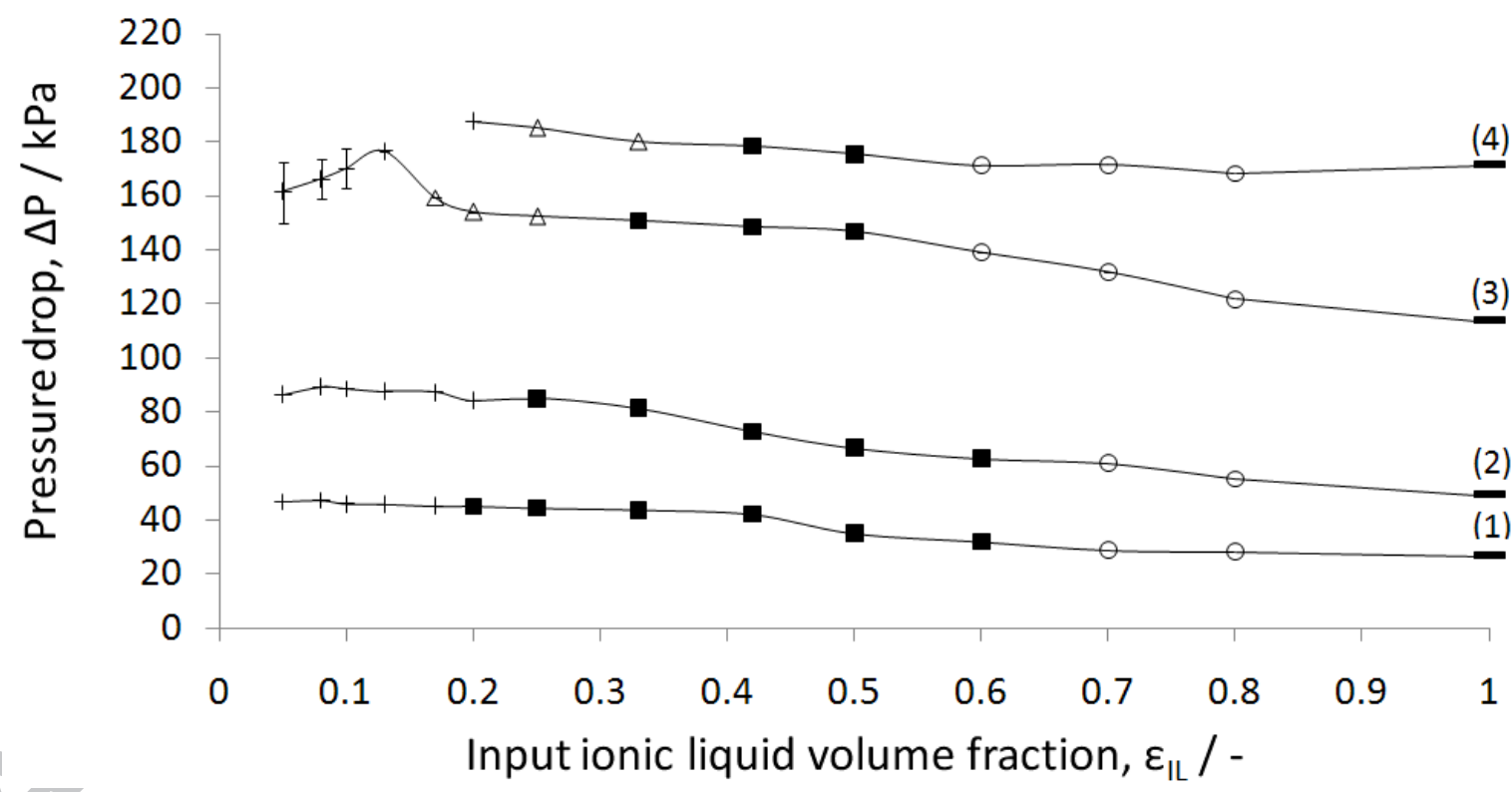

(b) Y-junction

Fig. 7. Two-phase pressure drop versus input ionic liquid volume fraction at different ionic liquid flow rates for the FEP microchannel and (a) T-junction, (b) Y-junction inlet. $Q_{\mathrm{IL}}:(1)=1.131 \mathrm{~cm}^{3} \mathrm{~h}^{-1},(2)=2.262 \mathrm{~cm}^{3} \mathrm{~h}^{-1},(3)=5.655 \mathrm{~cm}^{3} \mathrm{~h}^{-1},(4)=8.482 \mathrm{~cm}^{3} \mathrm{~h}^{-1}$ Flow pattern symbols: Annular (+), Plug (匹), Drop (०), Irregular ( $\Delta$ ) 


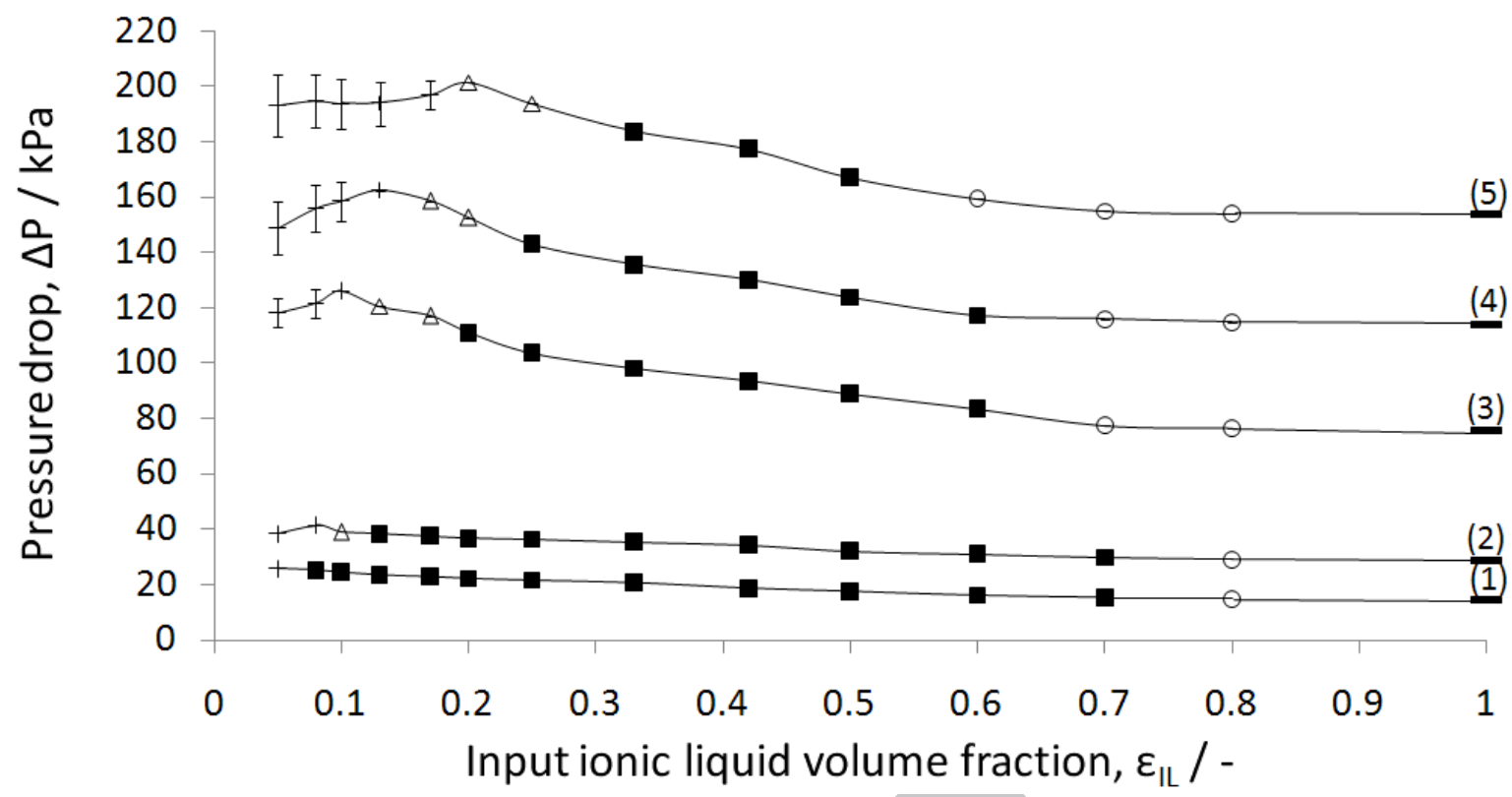

Fig. 8. Two-phase pressure drop versus input ionic liquid volume fraction at different ionic liquid flow rates for the Tefzel microchannel with T-junction as inlet.

$\mathrm{Q}_{\mathrm{IL}}: \quad(1)=1.131 \mathrm{~cm}^{3} \mathrm{~h}^{-1}, \quad(2)=2.262 \mathrm{~cm}^{3} \mathrm{~h}^{-1}, \quad(3)=5.655 \mathrm{~cm}^{3} \mathrm{~h}^{-1}, \quad(4)=8.482 \mathrm{~cm}^{3} \mathrm{~h}^{-1}$, (5) $=11.31 \mathrm{~cm}^{3} \mathrm{~h}^{-1}$

Flow pattern symbols: Annular (+), Plug (匹), Drop (०), Irregular $(\Delta)$ 


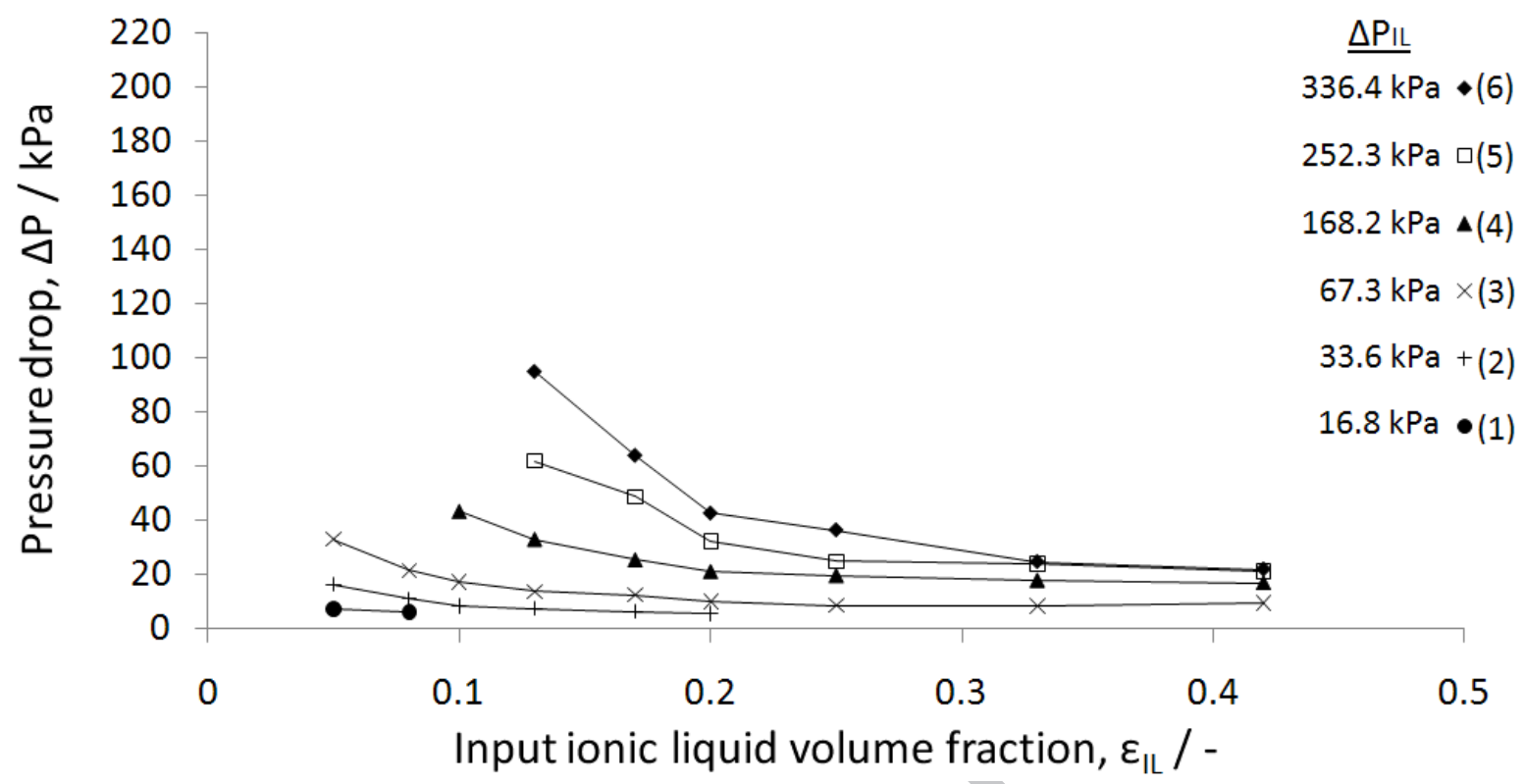

Fig. 9. Two-phase pressure drop versus input ionic liquid volume fraction during plug flow at different ionic liquid flow rates for the glass microchannel with a T-junction as inlet. The pressure drop values for single phase ionic liquid are given on the right $\mathrm{Q}_{\mathrm{IL}}: \quad(1)=1.131 \mathrm{~cm}^{3} \mathrm{~h}^{-1}, \quad(2)=2.262 \mathrm{~cm}^{3} \mathrm{~h}^{-1}, \quad(3)=5.655 \mathrm{~cm}^{3} \mathrm{~h}^{-1}, \quad$ (4) $=8.482 \mathrm{~cm}^{3} \mathrm{~h}^{-1}$, $(5)=11.31 \mathrm{~cm}^{3} \mathrm{~h}^{-1},(6)=11.31 \mathrm{~cm}^{3} \mathrm{~h}^{-1}$ 


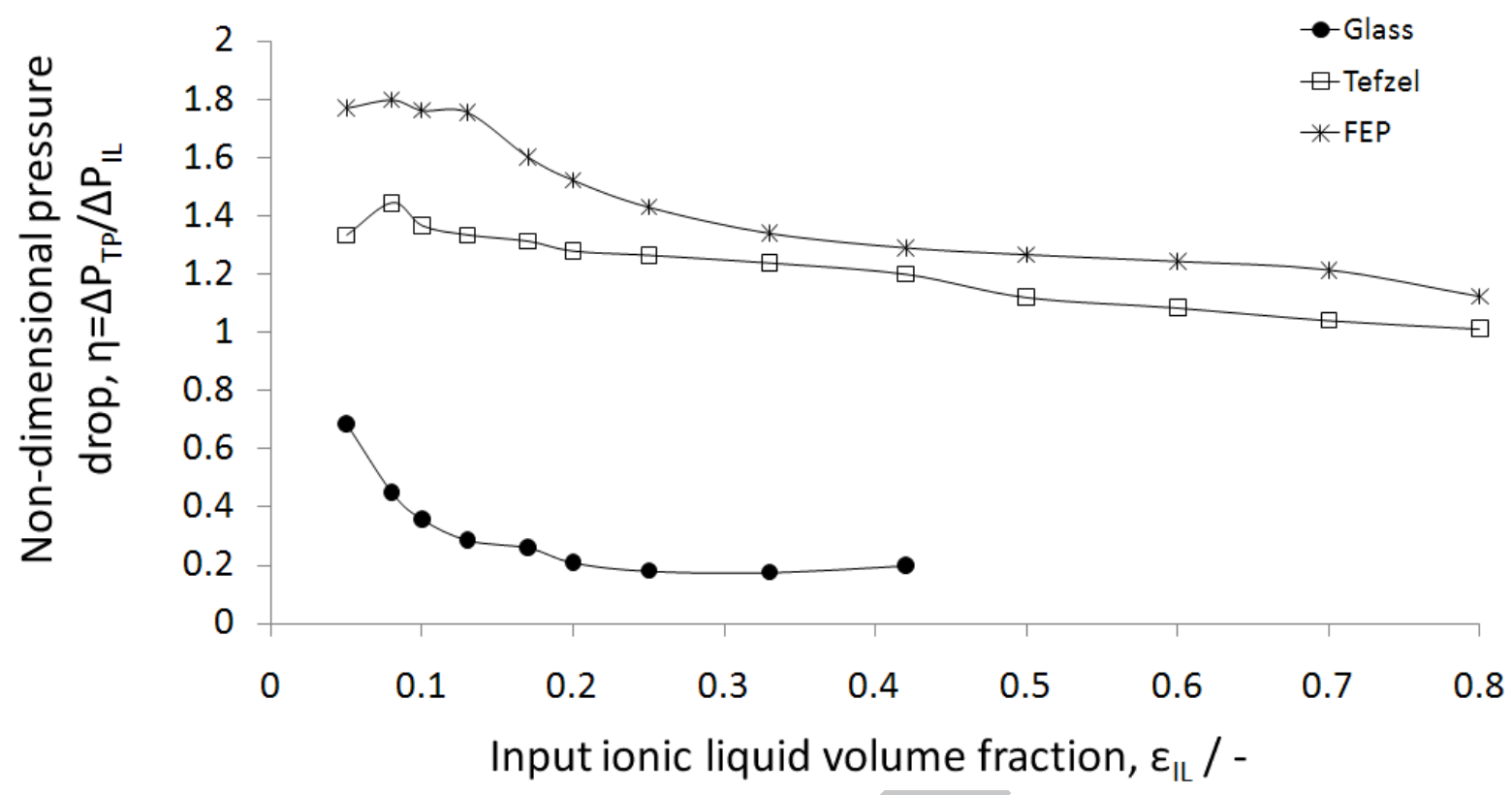

Fig. 10. Comparison of non-dimensional pressure drop in the FEP, Tefzel and glass microchannels with a T-junction as inlet, at a constant ionic liquid flow rate, $Q_{\mathrm{IL}}=2.262 \mathrm{~cm}^{3} \mathrm{~h}^{-1}$. 


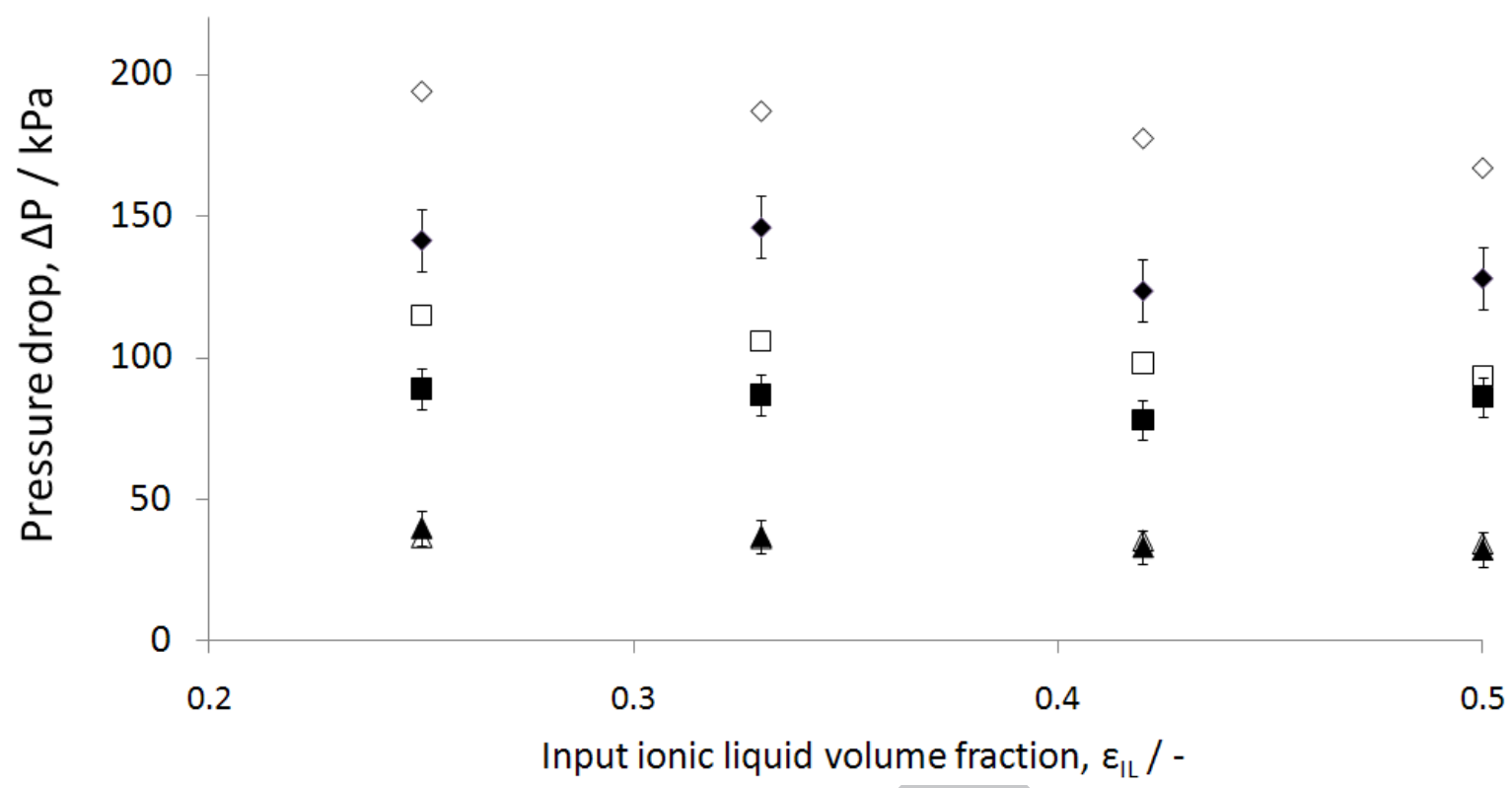

Fig. 11. Comparison of the pressure drop measurements obtained experimentally during plug flow with Kashid model. Symbols correspond to experimental data: $\Delta-\mathrm{Q}_{\mathrm{IL}}=2.262 \mathrm{~cm}^{3} \mathrm{~h}^{-1}$; $\square-$ $\mathrm{Q}_{\mathrm{IL}}=5.482 \mathrm{~cm}^{3} \mathrm{~h}^{-1} ; \diamond-\mathrm{Q}_{\mathrm{IL}}=8.482 \mathrm{~cm}^{3} \mathrm{~h}^{-1}$. Filled symbols correspond to theoretical values. 


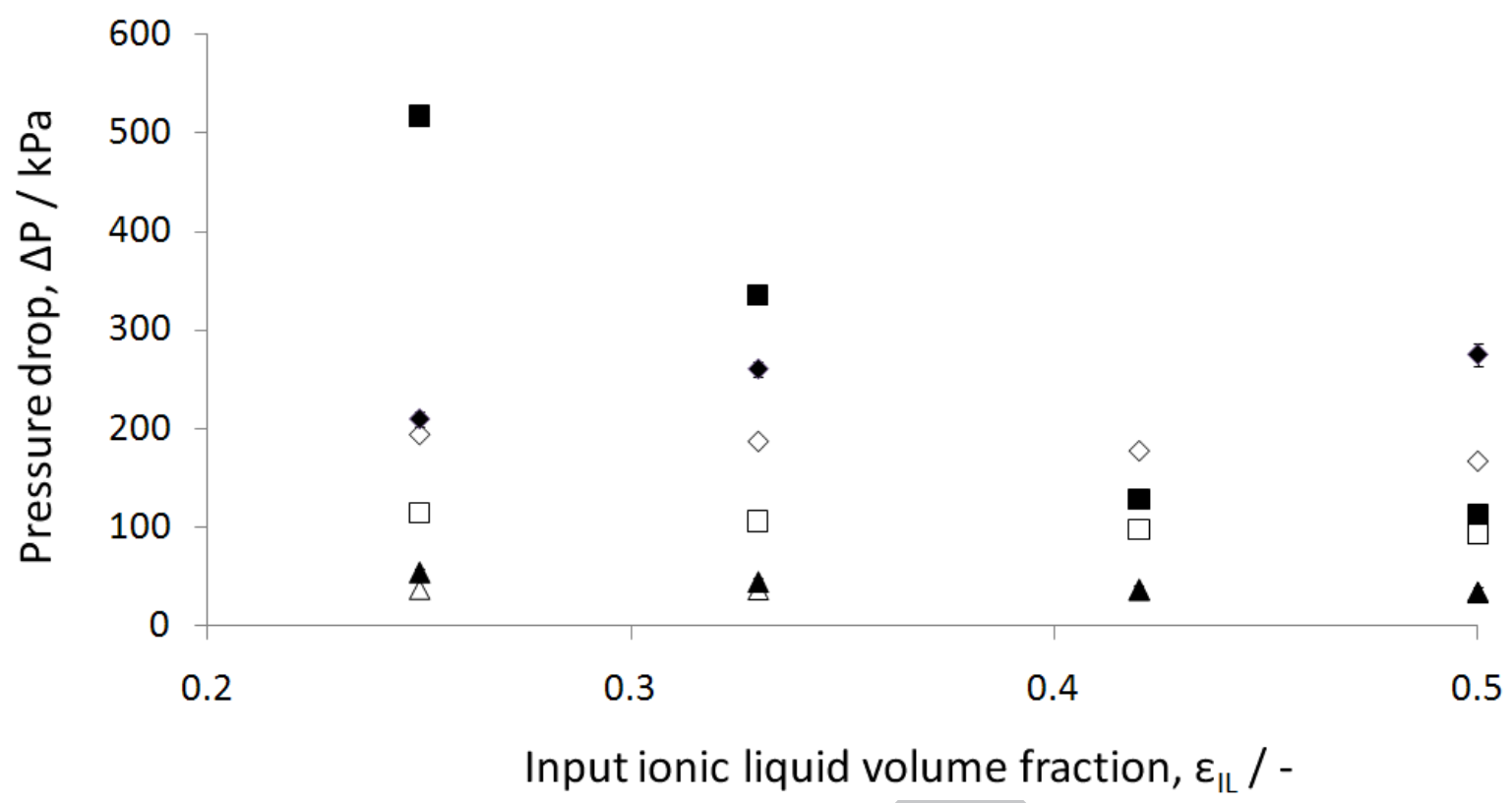

Fig. 12. Comparison of the pressure drop measurements obtained experimentally during plug flow with Jovanovic model. Symbols correspond to experimental data: $\Delta-\mathrm{Q}_{\mathrm{IL}}=2.262 \mathrm{~cm}^{3} \mathrm{~h}^{-1}$; $\square-\mathrm{Q}_{\mathrm{IL}}=5.482 \mathrm{~cm}^{3} \mathrm{~h}^{-1} ; \diamond-\mathrm{Q}_{\mathrm{IL}}=8.482 \mathrm{~cm}^{3} \mathrm{~h}^{-1}$. Filled symbols correspond to theoretical values. 


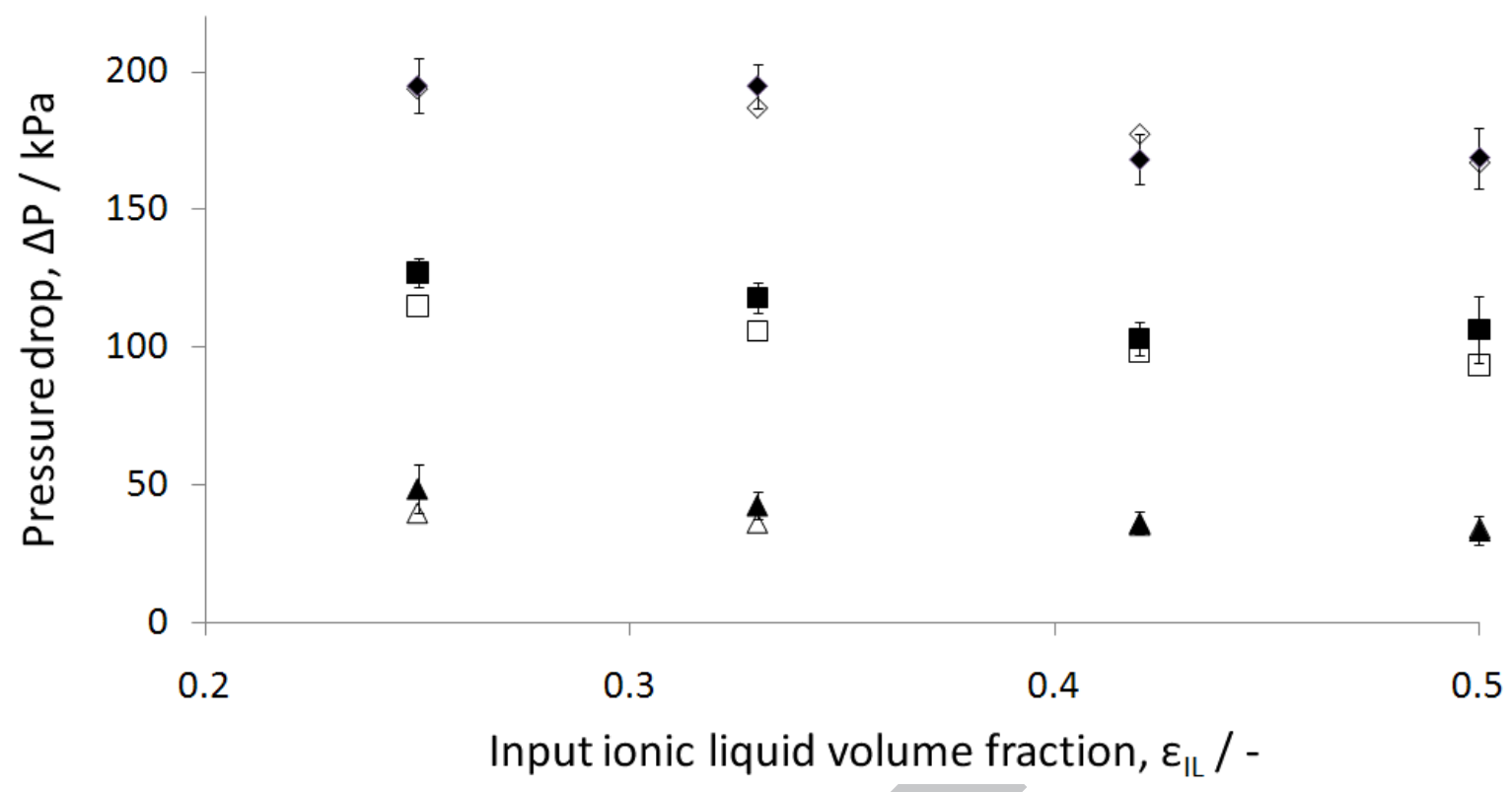

Fig. 13. Comparison of the pressure drop measurements obtained experimentally during plug flow with modified Jovanovic model. Symbols correspond to experimental data: $\Delta$ $\mathrm{Q}_{\mathrm{IL}}=2.262 \mathrm{~cm}^{3} \mathrm{~h}^{-1} ; \square-\mathrm{Q}_{\mathrm{IL}}=5.482 \mathrm{~cm}^{3} \mathrm{~h}^{-1} ; \diamond-\mathrm{Q}_{\mathrm{IL}}=8.482 \mathrm{~cm}^{3} \mathrm{~h}^{-1}$. Filled symbols correspond to theoretical values. 
Table 1. Dimensionless number for the characterisation of the two-phase flow.

\begin{tabular}{|c|c|}
\hline Dimensionless numbers & Definition \\
\hline Reynolds number & $\mathrm{Re}_{\mathrm{i}}=\frac{\rho_{\mathrm{i}} \mathrm{U}_{\mathrm{i}} \mathrm{ID}}{\mu_{\mathrm{i}}}=\frac{\text { inertia forces }}{\text { viscous forces }}$ \\
\hline Capillary number & $\mathrm{Ca}_{\mathrm{i}}=\frac{\mu_{\mathrm{i}} \mathrm{U}_{\mathrm{i}}}{\gamma}=\frac{\text { viscous forces }}{\text { interfacial forces }}$ \\
\hline Weber number & $\mathrm{We}_{\mathrm{i}}=\frac{\rho_{\mathrm{i}} \mathrm{U}_{\mathrm{i}}^{2} \mathrm{ID}}{\gamma}=\frac{\text { inertia forces }}{\text { interfacial forces }}$ \\
\hline Bond number & $\mathrm{Bo}=\frac{\mathrm{ID}^{2} \Delta \mathrm{pg}}{\gamma}=\frac{\text { buoyancy forces }}{\text { interfacial forces }}$ \\
\hline
\end{tabular}


Table 2. Properties of the test liquids.

\begin{tabular}{|c|c|c|c|}
\hline \multirow[b]{2}{*}{ Properties $\left(20^{\circ} \mathrm{C}\right)$} & \multicolumn{2}{|c|}{$\left[\mathrm{C}_{4} \mathrm{mim}\right]\left[\mathrm{NTf}_{2}\right]$} & \multirow[b]{2}{*}{ Deionised Water } \\
\hline & $\underline{\text { Pure }}$ & $\frac{\text { Water }}{\text { saturated }}$ & \\
\hline Viscosity, $\mu / \mathrm{kg} \mathrm{m}^{-1} \mathrm{~s}^{-1}$ & 0.052 & 0.041 & 0.001 \\
\hline Surface tension, $\sigma / \mathrm{N} \mathrm{m}^{-1}$ & $31.26 \cdot 10^{-3}$ & $31.55 \cdot 10^{-3}$ & $73.14 \cdot 10^{-3}$ \\
\hline Density, $\rho / \mathrm{kg} \mathrm{m}^{-3}$ & \multicolumn{2}{|c|}{1420} & 1000 \\
\hline Interfacial tension, $\gamma / \mathrm{N} \mathrm{m}^{-1}$ & \multicolumn{3}{|c|}{$12.29 \cdot 10^{-3}$} \\
\hline
\end{tabular}


Table 3. Contact angles $\left(\theta^{\circ}\right)$ on a borosilicate glass and Teflon plate.

\begin{tabular}{|c|c|c|c|}
\hline Foluid 1 & $\begin{array}{c}{\left[\mathrm{C}_{4} \text { mim }\right]\left[\mathrm{NTf}_{2}\right]-} \\
\text { Deionised water }\end{array}$ & $\begin{array}{c}{\left[\mathrm{C}_{4} \mathrm{mim}\right]\left[\mathrm{NTf}_{2}\right]-} \\
\text { Air }\end{array}$ & $\begin{array}{c}\text { Deionised } \\
\text { water-Air }\end{array}$ \\
\hline Borosilicate glass & $94^{\circ}$ & $43^{\circ}$ & $55^{\circ}$ \\
\hline Teflon & $70^{\circ}$ & $64^{\circ}$ & $102^{\circ}$ \\
\hline
\end{tabular}




\section{Research highlights}

- Flow patterns and pressure drop during ionic liquid-water flow in microchannels.

- Effect of channel wall wetting properties on flow patterns and pressure drop.

- Pressure drop in plug flow can be lower than that of single phase ionic liquids.

- Pressure drop in plug flow can be predicted from available models when experimental film thickness values are used. 